\title{
Krill Oil Treatment Increases Distinct PUFAs and Oxylipins in Adipose Tissue and Liver and Attenuates Obesity-Associated Inflammation via Direct and Indirect Mechanisms
}

\author{
Eveline Gart ${ }^{1,2, *(\mathbb{D}}$, Kanita Salic ${ }^{1}$, Martine C. Morrison ${ }^{1,2}{ }^{\mathbb{D}}$, Martien Caspers ${ }^{3} \mathbb{D}$, Wim van Duyvenvoorde ${ }^{1}$, \\ Marieke Heijnk ${ }^{4}$, Martin Giera ${ }^{4}\left(\mathbb{D}\right.$, Ivana Bobeldijk-Pastorova ${ }^{1}$, Jaap Keijer ${ }^{3} \mathbb{D}$, Andreas B. Storsve ${ }^{5}$, \\ Petter-Arnt Hals ${ }^{5}$ (D) and Robert Kleemann ${ }^{1,6}{ }^{(D)}$
}

check for updates

Citation: Gart, E.; Salic, K.; Morrison, M.C.; Caspers, M.; van

Duyvenvoorde, W.; Heijnk, M.; Giera M.; Bobeldijk-Pastorova, I.; Keijer, J.; Storsve, A.B.; et al. Krill Oil Treatment Increases Distinct PUFAs and Oxylipins in Adipose Tissue and Liver and Attenuates Obesity-Associated Inflammation via Direct and Indirect Mechanisms. Nutrients 2021, 13, 2836. https: / / doi.org/10.3390/nu13082836

Academic Editor: Andrew J. Sinclair

Received: 30 June 2021

Accepted: 16 August 2021

Published: 18 August 2021

Publisher's Note: MDPI stays neutral with regard to jurisdictional claims in published maps and institutional affiliations.

Copyright: (c) 2021 by the authors. Licensee MDPI, Basel, Switzerland. This article is an open access article distributed under the terms and conditions of the Creative Commons Attribution (CC BY) license (https:// creativecommons.org/licenses/by/ $4.0 /)$.
1 Department of Metabolic Health Research, The Netherlands Organisation for Applied Scientific Research (TNO), 2333 CK Leiden, The Netherlands; ekzs@novonordisk.com (K.S.); martine.morrison@tno.nl (M.C.M.); wim.vanduyvenvoorde@tno.nl (W.v.D.); ivana.bobeldijk@tno.nl (I.B.-P.); robert.kleemann@tno.nl (R.K.)

2 Human and Animal Physiology, Wageningen University, 6708 WD Wageningen, The Netherlands

3 Department of Microbiology and Systems Biology, The Netherlands Organization for Applied Scientific Research (TNO), 3704 HE Zeist, The Netherlands; martien.caspers@tno.nl (M.C.); jaap.keijer@wur.nl (J.K.)

4 Center for Proteomics and Metabolomics, Leiden University Medical Center, Albinusdreef 2, 2333 ZA Leiden, The Netherlands; m.heijink@lumc.nl (M.H.); m.a.giera@lumc.nl (M.G.)

5 Aker BioMarine Antarctic AS, Oksenøyveien 10, NO-1366 Lysaker, Norway; andreas.storsve@akerbiomarine.com (A.B.S.); petter-arnt.hals@akerbiomarine.com (P.-A.H.)

6 Department of Vascular Surgery, Leiden University Medical Center, 2333 ZA Leiden, The Netherlands

* Correspondence: eveline.gart@tno.nl; Tel.: +31-888663704

Abstract: The development of obesity is characterized by the metabolic overload of tissues and subsequent organ inflammation. The health effects of krill oil $(\mathrm{KrO})$ on obesity-associated inflammation remain largely elusive, because long-term treatments with $\mathrm{KrO}$ have not been performed to date. Therefore, we examined the putative health effects of 28 weeks of $3 \%(w / w) \mathrm{KrO}$ supplementation to an obesogenic diet (HFD) with fat derived mostly from lard. The HFD with KrO was compared to an HFD control group to evaluate the effects on fatty acid composition and associated inflammation in epididymal white adipose tissue (eWAT) and the liver during obesity development. KrO treatment increased the concentrations of EPA and DHA and associated oxylipins, including 18-HEPE, $\mathrm{RvE}_{2}$ and 14-HDHA in eWAT and the liver. Simultaneously, KrO decreased arachidonic acid concentrations and arachidonic-acid-derived oxylipins (e.g., HETEs, $\mathrm{PGD}_{2}, \mathrm{PGE}_{2}, \mathrm{PGF}_{2} \alpha, \mathrm{TXB}_{2}$ ). In eWAT, $\mathrm{KrO}$ activated regulators of adipogenesis (e.g., PPAR $\gamma, \mathrm{CEBP} \alpha, \mathrm{KLF} 15, \mathrm{STAT} 5 \mathrm{~A}$ ), induced a shift towards smaller adipocytes and increased the total adipocyte numbers indicative for hyperplasia. $\mathrm{KrO}$ reduced crown-like structures in eWAT, and suppressed HFD-stimulated inflammatory pathways including TNF $\alpha$ and CCL2/MCP-1 signaling. The observed eWAT changes were accompanied by reduced plasma leptin and increased plasma adiponectin levels over time, and improved insulin resistance (HOMA-IR). In the liver, $\mathrm{KrO}$ suppressed inflammatory signaling pathways, including those controlled by IL-1 $\beta$ and M-CSF, without affecting liver histology. Furthermore, KrO deactivated hepatic REL-A/p65-NF-kB signaling, consistent with increased PPAR $\alpha$ protein expression and a trend towards an increase in $\operatorname{IkB} \alpha$. In conclusion, long-term $\mathrm{KrO}$ treatment increased several anti-inflammatory PUFAs and oxylipins in WAT and the liver. These changes were accompanied by beneficial effects on general metabolism and inflammatory tone at the tissue level. The stimulation of adipogenesis by $\mathrm{KrO}$ allows for safe fat storage and may, together with more direct PPAR-mediated anti-inflammatory mechanisms, attenuate inflammation.

Keywords: krill oil; polyunsaturated fatty acids (PUFAs); obesity; inflammation; oxylipins; adipogenesis 


\section{Introduction}

Metabolic overload caused by excessive intake of energy-dense foods promotes the development of obesity, which is characterized by inflammation in white adipose tissue (WAT) and the liver [1]. During the development of obesity, WAT expands to store the energy surplus. This WAT expansion involves two processes: adipocyte hyperplasia (an increase in the cell number via adipogenesis) and adipocyte hypertrophy (an increase in cell size) [2]. Both processes have a physiological limit, and these vary between different WAT depots. The epididymal WAT (eWAT) of mice, for example, predominantly responds to metabolic overload with hypertrophy [3]. We and others have shown that the time point of maximal eWAT expansion coincides with the development of adipose tissue inflammation [3,4]. eWAT is thought to be particularly susceptible to becoming inflamed because of its limited ability to initiate the adipogenesis program required for hyperplasia. The development of hypertrophic and inflamed WAT is typically paralleled by changes in systemic inflammation markers, including cytokines (e.g., TNF- $\alpha$, Il-6) and adipokines [5]. These circulating factors can contribute to the development of insulin resistance as well as liver steatosis and inflammation in obese subjects [6]. Treatments that could correct metabolic imbalances and exert anti-inflammatory activities would be beneficial for all obesity-associated disorders.

Krill oil (KrO), a marine oil extracted from Antarctic krill, is rich in phospholipids ( $>55 \%$ of total lipids), most of which are phosphatidylcholines $(>85 \%)$. KrO has a high content of long-chain omega-3 polyunsaturated fatty acids (PUFAs), in particular eicosapentaenoic acid (EPA) and docosahexaenoic acid (DHA) [7]. Lipids from $\mathrm{KrO}$ can be stored in cells or converted intracellularly into a variety of bioactive oxylipins that can act as direct inflammatory modulators [8]. Many of the fatty acids (FAs) present in $\mathrm{KrO}$, as well as their metabolites, are ligands of transcriptional regulators, including peroxisome-proliferatoractivated receptors (PPARs) [9]. PPAR $\alpha$ and PPAR $\gamma$ are predominately expressed in the liver and WAT, respectively, where they control the expression of genes that are critical for metabolism and adipogenesis. In addition, PPARs have anti-inflammatory properties, and can repress NF-KB-mediated transcription via multiple mechanisms (including direct physical association and upregulation of the IкB $\alpha$ protein) [10-12]. Besides being a ligand for PPARs, KrO-derived EPA and DHA can displace arachidonic acid (ARA), an omega-6 FA with proinflammatory properties, from membranes and may also compete with ARA for further enzymatic processing [13]. Via these indirect mechanisms, EPA and DHA can attenuate the pro-inflammatory effects of ARA and its downstream metabolites, such as hydroxyeicosatetraenoic acids (HETEs), oxoeicosanoids (KETEs), prostaglandins (PGs), thromboxanes (TXs) and leukotrienes (LTs) [14]. Furthermore, EPA and DHA themselves can be enzymatically converted into inflammation-resolving mediators, including hydroxyeicosapentaenoic acids (HEPEs), hydroxy docosahexaenoic acids (HDHAs) and further into resolvins (RVs), protectins (PDs) and maresins (MaRs) [14].

In this study, our aim was to examine the putative health effects of long-term (28 weeks) $\mathrm{KrO}$ supplementation $(3 \% w / w)$ in mice, since the health effects of $\mathrm{KrO}$ on obesityassociated organ inflammation remain largely elusive due to the lack of long-term treatment studies using physiologically relevant KrO concentrations. A small number of relatively short studies (less than 12 weeks of KrO treatment [15-19]) consistently point to an improvement of metabolic homeostasis and metabolic risk factors. To gain a better mechanistic insight into how $\mathrm{KrO}$ exerts its effects, we analyzed WAT and the liver by means of genome-wide mRNA sequencing to identify molecular pathways and critical upstream regulators. Furthermore, both tissues were subject to a comprehensive fatty acid composition analysis, including oxylipins using LC-MS/MS. Ldlr-/ - Leiden mice were chosen as a model because these mice develop obesity in combination with pronounced hyperinsulinemia and adipose tissue and liver inflammation when treated with energy-dense diets for 28 weeks (to allow for the histological analysis of organ inflammation) with a human-diet-like macronutrient composition, not requiring dietary supplementation with cholesterol [20-23]. Under the experimental conditions employed herein, Ldlr- / - Leiden 
mice have been shown to develop histopathological features similar to humans and they recapitulate human disease pathways, as demonstrated by recent comparative transcriptomics, metabolomics and proteomics studies $[21,22,24]$. We show that long-term $\mathrm{KrO}$ treatment markedly affects the tissue levels of PUFAs and oxylipins, and consistently with this, reduces their inflammatory tone.

\section{Materials and Methods}

\subsection{Animals, Diets and Study Design}

All animal experiments were performed in accordance with the Animal Care and Use Committee and ethical approval by an independent Animal Welfare Body (IVD TNO; approval number 3682/TNO-274). Male Ldlr-/ - Leiden mice were obtained from the breeding facility of TNO Metabolic Health Research, Leiden, The Netherlands. All mice were group-housed in an AAALAC-accredited animal facility (relative humidity 50-60\%, temperature $\sim 2{ }^{\circ} \mathrm{C}$, light cycle $7 \mathrm{am}$ to $7 \mathrm{pm}$ ) and had ad libitum access to food and water. Body weight and blood glucose data obtained before the start of dietary treatment were used to match mice into three comparable groups, to ensure that group differences at the end were attributable to the treatment they received during the study and not due to differences at baseline. The control group $(n=15)$ was treated with an energy-dense high-fat diet (HFD; D12451, Research Diets Inc.; $20 \mathrm{kcal} \%$ protein, $35 \mathrm{kcal} \%$ carbohydrate, $45 \mathrm{kcal} \%$ fat, with $39 \mathrm{kcal} \%$ from lard and $6 \mathrm{kcal} \%$ from soybean oil). The $\mathrm{KrO}$ treatment group received an HFD in which $3 \%$ of the total diet was replaced with $\mathrm{KrO}$ (KrO diet). The KrO (Superba Boost, Aker BioMarine Antarctic ASA, Lysaker, Norway) itself contained EPA $\geq 150 \mathrm{mg} / \mathrm{g}$ and DHA $\geq 70 \mathrm{mg} / \mathrm{g}$, which is approximately $20 \%$ of EPA and DHA fatty acids in KrO. Fatty acids are structural components of lipid species that are efficiently taken up in the intestine (phospholipids). $\mathrm{KrO}$ is a marine oil that is particularly rich in phospholipids and the $\mathrm{KrO}$ used in this study contained $\geq 560 \mathrm{mg} / \mathrm{g}$ phospholipids, of which $\geq 480 \mathrm{mg}$ was phosphatidylcholine. At an expected average daily intake of $3 \mathrm{~g}$ diet per mouse, the dietary intake of $\mathrm{KrO}$ was $0.09 \mathrm{~g} /$ mouse/day on average. HFD and $\mathrm{KrO}$ diets were isocaloric. A reference group remained on a low-fat control chow diet $(n=6)$ (chow; Ssniff-Spezialdiäten GmbH, Soest, Germany).

Body weight and food intake were measured regularly, and body composition was determined using echoMRI (EchoMRI-LLC, Houston, TX, USA). Blood samples were taken from the tail vein at the start of the study and after 8 weeks, 16 weeks and 28 weeks. In week 28, animals were terminated after $5 \mathrm{~h}$ fasting via gradual-fill $\mathrm{CO}_{2}$ asphyxiation and a terminal blood sample was collected via cardiac puncture. Isolated adipose and liver tissues were fixed in formalin and paraffin-embedded for histological analysis, or snap-frozen and stored at $-80^{\circ} \mathrm{C}$ for gene expression, lipid and protein analyses.

\subsection{Blood Chemistry}

Analyses of cholesterol, triglycerides, insulin, leptin, adiponectin, ALAT in fasting EDTA plasma and blood glucose were performed as described previously [22]. The blood sampling over time allowed us to calculate area under the curve (AUC) values of plasma parameters (GraphPad Prism, version 8 for Windows, GraphPad Software, La Jolla, CA, USA, www.graphpad.com, accessed on 23 March 2021). Free fatty acids (FFAs) were measured in orlistat (1 mg/L; Sigma-Aldrich, St. Louis, MO, USA) [25]-treated plasma and quantified with the NEFA-HR kit (Instruchemie, Delfzijl, The Netherlands).

\subsection{Total Fatty Acid Composition Analysis in Dry Blood Spots, White Adipose Tissue and Liver}

Dry blood spots (DBSs) collected during blood sampling, as well as tissue collected at sacrifice from eWAT and the liver, were analyzed for their fatty acid composition (OmegaQuant Analytics, Sioux Falls, SD, USA). Briefly, blood was collected during blood sampling after 28 weeks of treatment on filter paper pre-treated with an antioxidant cocktail (Fatty Acid Preservative Solution) and dried at room temperature for $15 \mathrm{~min}$. Tissue samples were weighed and transferred into screw-cap glass vials that contained tritricosanoin 
as an internal standard (tri-C23:0 TG) (NuCheck Prep, Elysian, MN, USA). These tissues were homogenized and then extracted with a modified Folch extraction. A portion of the organic layer was transferred to a screw-cap glass vial and dried in a speed vac. The dried tissue samples and a punch of the DBS filter paper in screw-cap glass vials were treated with BTM solution (methanol containing 14\% boron trifluoride, toluene, methanol; 35:30:35 $v / v / v$ ) (Sigma-Aldrich). The vial was briefly vortexed and heated ( $100{ }^{\circ} \mathrm{C}$ for $\left.45 \mathrm{~min}\right)$. After cooling, hexane (EMD Chemicals, New Hampshire, MA, USA) and HPLC-grade water were added, and samples were vortexed and centrifuged to separate layers. An aliquot of the hexane layer was used for gas chromatography (GC). GC was carried out using a GC-2010 (Shimadzu Corporation, Columbia, MD, USA) equipped with a SP-2560, 100-m fused silica capillary column $(0.25 \mathrm{~mm}$ internal diameter, $0.2 \mu \mathrm{m}$ film thickness; Supelco, Bellefonte, PA, USA). Fatty acids were identified and calibrated using a standard mixture of defined fatty acids (GLC OQ-A, NuCheck Prep). Fatty acid composition was expressed relatively (percentage of total identified fatty acids) and given in absolute concentrations ( $\mu \mathrm{g}$ fatty acid per mg WAT or liver tissue).

\subsection{Free Fatty Acids and Lipid Mediator Composition in White Adipose Tissue and Liver}

White adipose and liver tissues from sacrificed mice were homogenized in water at a concentration of $0.33 \mathrm{mg} / \mu \mathrm{L}$ (Biosolve, Valkenswaard, The Netherlands). WAT (10 mg) or liver tissue $(2.7 \mathrm{mg}$ ) homogenates were mixed with $600 \mu \mathrm{L} \mathrm{MeOH}$ (Merck, Darmstadt, Germany) containing internal standards (0.33 ng/mL PGE $-\mathrm{d} 4, \mathrm{LTB}_{4}$-d4, 15-HETE-d8, 14(15)-EET-d11, $0.66 \mathrm{ng} / \mathrm{mL}$ 8-iso-PGF 2 alpha-d4 and $3.3 \mathrm{ng} / \mathrm{mL}$ DHA-d5, all Cayman Chemical, Ann Abor, MI, USA) and $200 \mu \mathrm{L}$ water was added to the mixture. Samples were incubated for $20 \mathrm{~min}$ at $-20^{\circ} \mathrm{C}$ and centrifuged $\left(10 \mathrm{~min}\right.$ at $\left.16.100 \times g, 4^{\circ} \mathrm{C}\right)$. Supernatant was diluted with water, acidified to $\mathrm{pH} \pm 3.0$ using formic acid (VWR, Darmstadt, Germany) and applied to C18 SPE cartridges (Sep-Pak C18, $200 \mathrm{mg}, 3$ cc, Waters, Milford, MA, USA). The obtained samples were cleaned consecutively with water and $n$-hexane (VWR) and eluted using methyl formate (Sigma-Aldrich). The eluate was dried at $40{ }^{\circ} \mathrm{C}$ under a stream of nitrogen and reconstituted in $40 \% \mathrm{MeOH}$. Samples were analyzed using an LC-MS/MS system consisting of two LC-30AD pumps, a SIL-30AC autosampler and a CTO-20AC column oven (All Shimadzu, Hertogenbosch, The Netherlands). Samples were injected with an autosampler (at $6^{\circ} \mathrm{C}$ ) and separated on a Kinetex C18 column (Phenomenex, Aschaffenburg, Germany, $50 \times 2.1 \mathrm{~mm}, 1.7 \mu \mathrm{m}$ ) using a gradient of $0.01 \%$ acetic acid (Fluka, Darmstadt, Germany) in water (Honeywell-Riedel de Haën, Seelze, Germany; eluent A) and $0.01 \%$ acetic acid in $\mathrm{MeOH}$ (eluent $\mathrm{B}$ ) with the oven at $50{ }^{\circ} \mathrm{C}$. The gradient was as follows: $0.0-1.0 \mathrm{~min}$ constant at 30\% B, 1.0-1.1 min linear increase to 45\% B, 1.1-2.0 min linear increase to $53.5 \% \mathrm{~B}, 2.0-4.4 \mathrm{~min}$ linear increase to $55.5 \% \mathrm{~B}, 4.0-7.0 \mathrm{~min}$ linear increase to $90 \%$ B, 7.0-7.1 min linear increase to $100 \%$ B, 7.1-9.0 min constant at $100 \%$ B, 9.0-9.5 min linear decrease to $30 \%$ B, 9.5-11.5 min constant at 30\% B. Detection was achieved on a Qtrap 6500 (Sciex Nieuwerkerk a/d, IJssel, The Netherlands) equipped with an ESI source. The MS was operated in negative scheduled MRM mode, with the source needle voltage at $-4500 \mathrm{~V}$, drying temperature of $450{ }^{\circ} \mathrm{C}$, ion source gas 1 and 2 (both air) at respectively 40 and 30 psi and the nitrogen nebulizer gas at 30 psi. The entrance potential was set to $10 \mathrm{~V}$ and the collision gas flow to 'medium'. Individually optimized parameters for each compound can be found in Supplementary Table S1.

The detected lipid mediators PDX and $\mathrm{RvE}_{2}$ were identified based on comparisons with authentic standard material. Both substances showed closely matching $(<0.5 \%$ deviation) relative retention times between samples and authentic standard material. Furthermore, the tandem mass spectra for PDX were closely matched (Supplementary Figure S1). In the case of $\mathrm{RvE}_{2}$, we monitored four characteristic fragment ions of $\mathrm{RvE}_{2}$ by means of a dedicated product ion scan LC-MS/MS method. The obtained relative retention times and ion ratios were also compared with authentic standard material (Supplementary Figure S2). Standards of $\mathrm{RvE}_{1}, \mathrm{RvE}_{2}, 18(\mathrm{R})-\mathrm{RvE}_{3}$ and $18(\mathrm{~S})-\mathrm{RvE}_{3}$ were gifts from Dr. Makoto Arita (Tokyo, Japan); all other standards were obtained from Cayman Chemicals. 


\subsection{Histological Analysis of Adipose Tissue and Liver}

Paraffin-embedded 5- $\mu \mathrm{m}$-thick cross sections of eWAT were stained with hematoxylinphloxine-saffron and scanned for digital analysis (Aperio AT2, Leica Biosystems, Amsterdam, The Netherlands). Cell size and counts of adipocytes were analyzed using Adiposoft [26]. Inflammation was quantified by scoring the amount of crown-like structures (CLS) and expressed as the number of CLS/1000 adipocytes, as described previously in detail [27]. The calculation of total eWAT cell numbers as a measure of hyperplasia was performed using a well-established mathematical model [28].

The histopathological analysis of liver steatosis and hypertrophy was performed on 3- $\mu \mathrm{m}$-thick hematoxylin-eosin-stained cross sections of the medial lobe using a standardized method for rodent liver histopathology, based on the human NAS scoring system $[29,30]$. The percentages of the total liver sections affected by steatosis and hypertrophy translate into the NAS categories of severity as follows: $0(<5 \%), 1(5-33 \%), 2(34-66 \%)$ and $3(>66 \%)$ [29]. In addition, F4/80 immunostaining was performed on the liver sections as detailed in [21] and the number of F4/80-positive CLSs was counted in three nonoverlapping fields and expressed per $\mathrm{mm}^{2}$.

\subsection{Liver Biochemistry}

Total hepatic triglyceride content was determined in crude liver homogenates by following the Bligh and Dyer method for lipid extraction with methanol and chloroform [31]. In the same liver homogenates, protein levels were determined, using a Lowry protein assay. The lipids were separated by means of high-performance liquid chromatography (HPTLC) on silica gel plates and stained with color reagent $\left(5 \mathrm{~g}\right.$ of $\mathrm{MnCl}_{2} \bullet 4 \mathrm{H}_{2} \mathrm{O}, 32 \mathrm{~mL}$ of $95-97 \% \mathrm{H}_{2} \mathrm{SO}_{4}$ added to $960 \mathrm{~mL}$ of $\mathrm{CH}_{3} \mathrm{OH}: \mathrm{H}_{2} \mathrm{O} 1: 1 \mathrm{v} / \mathrm{v}$ ). The liver triglyceride bands were quantified with a ChemiDoc Touch Imaging System (Bio-Rad, Hercules, CA, USA) using Image-lab version 5.2.1 software (Bio-Rad) and were expressed per mg protein.

\subsection{Genome-Wide Gene Expression Analysis}

Next generation sequencing (NGS) was performed essentially as described [21]. Briefly, total RNA was extracted from eWAT using an Ambion RNAqueous total RNA isolation kit (Thermo Fisher Scientific, Waltman, MA, USA) and from the liver using the RNA-Bee total-RNA isolation kit (Bio-Connect, Huissen, The Netherlands), and was subsequently purified using PureLink RNA Mini Kit (Thermo Fisher Scientific). The RNA concentration was determined spectrophotometrically using a Nanodrop 1000 (Isogen Life Science, De Meern, The Netherlands), and RNA quality was assessed using a 2100 Bioanalyzer (Agilent Technologies, Amstelveen, The Netherlands). Strand-specific messenger RNA sequencing libraries were multiplexed, clustered and sequenced on a Nextseq500 V2 system (Illumina, San Diego, CA, USA) at Genomescan (Leiden, The Netherlands). The sequenced, annotated and aligned gene counts served as inputs for the differentially expressed gene (DEG) analysis using the Deseq2-method [32]. The integrity of the gene expression datasets from eWAT and the liver were analyzed (e.g., distance matrix and principal component analysis) and $10 \%$ technical outliers were excluded. For the subsequent bioinformatical analysis, $n=5$ chow, $n=9$ HFD and $n=9 \mathrm{KrO}$ liver samples, as well as $n=5$ chow, $n=8$ HFD and $n=10 \mathrm{KrO}$ eWAT samples, were used. DEGs were used as inputs for pathway analysis through Ingenuity Pathway Analysis (IPA; www.ingenuity.com, accessed on 23 March 2021). IPA uses gene expression data of all known downstream target genes to predict the activation or deactivation of an upstream regulator. Z-scores greater than 2 indicate the enhanced activity of an upstream regulator, whereas a Z-score less than -2 indicates the reduced activity of an upstream regulator [21]. The $p$-value indicates the significance of the gene enrichment of these upstream regulators.

\subsection{Western Blot Analysis}

Liver tissue from HFD- and KrO-treated mice ( $n=4$ /group) were homogenized in lysis buffer containing $150 \mathrm{mM} \mathrm{NaCL}, 1 \mathrm{mM}$ EDTA PH = 8, $50 \mathrm{mM}$ Tris-HCL PH = 7.4, 
1\% Igepal, 0.25\% deoxycholate, 0.1\% SDS, $1 \mathrm{mM} \mathrm{PMSF,} 1 \mathrm{mM} \mathrm{Na} \mathrm{VO}_{4}$ and complete mini EDTA-free protease inhibitor (Roche, Mannheim, Germany). Homogenates were centrifuged at 13,000 rpm for $15 \mathrm{~min}$ at $4{ }^{\circ} \mathrm{C}$, and the protein content of the supernatant was determined using the BCA Protein Assay Kit (Thermo Fisher Scientific). Proteins (50 ug) in $2 \times$ SDS Laemmli Sample Buffer (1:1 v/v; Sigma-Aldrich) were boiled for $5 \mathrm{~min}$ at $95^{\circ} \mathrm{C}$. Subsequently, samples were separated on a 4-20\% $(w / v)$ SDS-page gel (mini-Protean TGX stain-free precast gels; Bio-Rad). Proteins were transferred onto Trans-blot Turbo mini PVDF blotting membranes (Bio-Rad) using the MIXED MW program on the Trans-blot Turbo Bio-Rad machine. The blotting membranes were blocked for $1 \mathrm{~h}$ with $5 \%(w / v)$ milk powder in tris-buffered saline with $0.1 \%$ Tween 20 and incubated overnight at $4{ }^{\circ} \mathrm{C}$ with either the primary antibody $\mathrm{I} \kappa \mathrm{B} \alpha$ (\#9242S-1:1000 v/v; Cell Signaling, Leiden, The Netherlands), PPAR $\alpha$ (ab24509-1:1000 v/v; Abcam, Cambridge, UK) or $\alpha$ Tubulin (T51681:1000 $v / v$; Sigma-Aldrich). Secondary antibody (anti-mouse HRP conjugate \#7076S1:2000 $v / v$ or anti-rabbit HRP conjugate \#7074S-1:2000 v/v; Cell Signaling) was added and SuperSignal West Femto (Thermo Fisher Scientific) was used to visualize protein bands. Blots were analyzed with a ChemiDoc Touch Imaging system (Bio-Rad) and band intensities were normalized to $\alpha$ Tubulin.

\subsection{Statistical Analysis}

All data shown are presented as mean \pm standard deviation (SD). The experiments investigated the null hypothesis that $\mathrm{KrO}$ does not have beneficial effects on disease parameters relative to controls (HFD). Therefore, $\mathrm{KrO}$ was compared to the HFD control group, and data from chow mice were provided as a reference. The significance of differences between $\mathrm{KrO}$ and HFD was tested using one-sided $t$-tests $(\alpha=0.05)$ if the data were normally distributed with equal variances. Data sets that were not normally distributed or with unequal variances were tested with a Mann-Whitney U test. IPA analysis to determine differentially expressed genes were based on Fisher's exact test $(\alpha=0.01)$.

\section{Results}

\subsection{Long-Term KrO Treatment Improves Lipid Composition in Blood, eWAT and Liver Tissue}

During 28 weeks of HFD feeding, body weight increased from $29.4 \mathrm{~g}$ to $52.7 \mathrm{~g}$ in the HFD control group. EchoMRI analysis showed that the observed weight gain relative to chow could mainly be ascribed to an increase in fat mass (Table 1). KrO treatment had no effect on body weight development, total fat mass or absolute mass of eWAT or subcutaneous WAT (sWAT), whereas the mesenteric WAT (mWAT) mass was significantly lower than in HFD. The energy intake was comparable in all groups. Plasma lipids were significantly elevated by the HFD compared with chow, indicating a state of hyperlipidemia, and were not affected by $\mathrm{KrO}$ (Table 1$)$.

Table 1. Body composition, energy intake and plasma lipids.

\begin{tabular}{cccc}
\hline & Chow & HFD & KrO \\
\hline BW (g) & $41.6 \pm 6.6^{*}$ & $52.7 \pm 4.4$ & $50.9 \pm 2.9$ \\
Fat mass (g) & $11.0 \pm 3.3^{*}$ & $23.2 \pm 2.9$ & $21.4 \pm 2.4$ \\
Lean mass (g) & $29.0 \pm 3.6^{*}$ & $29.6 \pm 2.7$ & $29.9 \pm 1.8$ \\
eWAT (g) & $1.9 \pm 0.5$ & $2.0 \pm 0.5$ & $1.9 \pm 0.3$ \\
sWAT (g) & $1.1 \pm 0.3^{*}$ & $2.5 \pm 0.6$ & $2.4 \pm 0.4$ \\
mWAT (g) & $0.7 \pm 0.3^{*}$ & $1.2 \pm 0.3$ & $0.9 \pm 0.2^{*}$ \\
EI (kcal/mouse/day) & $13.1 \pm 1.1$ & $13.9 \pm 1.1$ & $14.2 \pm 0.5$ \\
FI (g/mouse/day) & $4.3 \pm 0.4^{*}$ & $2.9 \pm 0.2$ & $3.0 \pm 0.1$ \\
Cholesterol (mM) & $7.6 \pm 2.2^{*}$ & $34.2 \pm 13.0$ & $43.3 \pm 18.5$ \\
Triglycerides (mM) & $1.7 \pm 0.6^{*}$ & $6.0 \pm 3.4$ & $6.6 \pm 4.8$ \\
\hline
\end{tabular}

Body composition, food intake and plasma lipids after 28 weeks of dietary treatment. BW: body weight; EI: energy intake; FI: food intake; eWAT: epididymal white adipose tissue (WAT); sWAT: subcutaneous WAT; mWAT mesenteric WAT. In the left column, data from the chow group are provided for reference. Data are presented as mean $\pm \mathrm{SD}, * p<0.05$ compared to HFD. HFD: high-fat diet. 
To assess whether $\mathrm{KrO}$ altered the omega-3 FA content in the circulation, we analyzed the FA composition in dry blood spots (Supplementary Table S2). Compared to HFD, KrO treatment significantly increased the relative amounts of omega-3 FAs, with marked effects on EPA (19.8-fold) and DHA (1.5-fold).

We next examined whether similar changes would occur at the tissue level (Table 2). In eWAT, $\mathrm{KrO}$ treatment increased the absolute tissue concentrations of EPA (13.7-fold) and DHA (3.6-fold) and other omega-3 FAs measured. KrO had comparable effects in the liver, where it increased EPA (10.8-fold) and DHA (2.0-fold) concentrations. Table 2 also demonstrates that the absolute concentrations of EPA and DHA were lower in eWAT than in the liver.

Table 2. Fatty acid concentrations in eWAT and the liver.

\begin{tabular}{|c|c|c|c|c|c|c|}
\hline \multirow[b]{2}{*}{ Fatty Acids (Ug/Mg Tissue) } & \multicolumn{3}{|c|}{ eWAT } & \multicolumn{3}{|c|}{ Liver } \\
\hline & Chow & HFD & $\mathrm{KrO}$ & Chow & HFD & $\mathrm{KrO}$ \\
\hline \multicolumn{7}{|l|}{ Omega-3 } \\
\hline Alpha-Linolenic (ALA) C18:3n3 & $11.0 *$ & 4.8 & $5.5^{*}$ & 0.7 & 0.7 & 0.9 * \\
\hline Eicosapentaenoic (EPA) C20:5n3 & $0.3^{*}$ & 0.1 & $1.5^{*}$ & $0.3 *$ & 0.2 & $2.5 *$ \\
\hline Docosapentaenoic n3 C22:5n3 & 0.8 & 0.5 & $1.6^{*}$ & 0.5 * & 0.6 & 2.0 * \\
\hline Docosahexaenoic (DHA) C22:6n3 & $1.9 *$ & 1.1 & $4.0 *$ & 3.7 & 3.9 & $7.6^{*}$ \\
\hline \multicolumn{7}{|l|}{ Omega-6 } \\
\hline Linoleic (LA) C18:2n6 & $214.0^{*}$ & 169.3 & 173.5 & $16.7^{*}$ & 28.1 & 25.2 \\
\hline gamma-Linolenic C18:3n6 & 0.7 & 0.7 & 0.6 & $0.3 *$ & 0.6 & $0.3^{*}$ \\
\hline Eicosadienoic C20:2n6 & $1.1^{*}$ & 2.5 & $2.4^{*}$ & 0.3 * & 0.7 & $0.6^{*}$ \\
\hline Dihomo-g-linolenic C20:3n6 & $1.9^{*}$ & 1.3 & $1.1 *$ & $1.0 *$ & 1.6 & $1.2 *$ \\
\hline Arachidonic (ARA) C20:4n6 & $3.6^{*}$ & 3.2 & $1.3^{*}$ & $5.3 *$ & 6.6 & $3.2 *$ \\
\hline Docosatetraenoic C22:4n6 & $0.5^{*}$ & 0.7 & $0.2 *$ & $0.3 *$ & 1.0 & $0.3 *$ \\
\hline Docosapentaenoic n6 C22:5n6 & 0.3 & 0.3 & $0.1^{*}$ & 0.1 & 0.5 & 0.0 * \\
\hline \multicolumn{7}{|l|}{ Cis-Monosaturated } \\
\hline Palmitoleic C16:1n7 & $79.8^{*}$ & 32.8 & 34.1 & 5.0 & 5.9 & 6.8 \\
\hline Oleic C18:1n9 & $288.8^{*}$ & 427.2 & 411.8 & $29.2^{*}$ & 86.1 & 72.5 \\
\hline Eicosenoic C20:1n9 & $4.9 *$ & 3.9 & $3.5^{*}$ & $0.7 *$ & 2.1 & $1.7^{*}$ \\
\hline Nervonic C24:1n9 & 0.1 * & 0.1 & 0.1 & 0.1 & 0.1 & 0.1 * \\
\hline \multicolumn{7}{|l|}{ Saturated } \\
\hline Myristic C14:0 & $7.7^{*}$ & 5.5 & $6.4^{*}$ & $0.5^{*}$ & 1.0 & $0.8^{*}$ \\
\hline Palmitic C16:0 & 152.6 & 133.4 & 130.3 & $21.4 *$ & 46.4 & $38.6 *$ \\
\hline Stearic C18:0 & $9.0 *$ & 21.9 & 20.6 & $5.0 *$ & 5.9 & 5.4 * \\
\hline Arachidic C20:0 & 0.3 * & 0.2 & 0.2 & 0.2 & 0.2 & 0.3 \\
\hline Behenic C22:0 & 0.1 & 0.0 & 0.0 & 0.1 * & 0.0 & $0.1^{*}$ \\
\hline Lignoceric C24:0 & $0.0 *$ & 0.0 & 0.0 & 0.0 * & 0.0 & $0.0 *$ \\
\hline \multicolumn{7}{|l|}{ Trans } \\
\hline Palmitelaidic C16:1n7t & 0.8 & 0.7 & $0.9^{*}$ & $0.1^{*}$ & 0.1 & $0.2 *$ \\
\hline Elaidic C18:1t & $0.7^{*}$ & 1.9 & $1.6^{*}$ & 0.1 * & 0.3 & 0.2 * \\
\hline Linoelaidic C18:2n6t & 2.0 & 1.6 & 1.5 & 0.3 * & 0.5 & 0.3 * \\
\hline
\end{tabular}

Fatty acid concentrations determined in eWAT and liver tissue after 28 weeks of dietary treatment. The types of fatty acids are indicated in bold. In the left column, data from the chow group are provided for reference. Average fatty acid concentrations significantly higher compared to the HFD control group are shown in orange, and significantly lower concentrations are shown in green $(* p<0.05)$.

By contrast, $\mathrm{KrO}$ treatment significantly reduced ARA concentrations in the circulation by $59 \%$ compared to HFD (0.4-fold reduction), i.e., below the levels of chow reference mice (Supplementary Table S2). In WAT and the liver, $\mathrm{KrO}$ had similar effects and strongly reduced ARA tissue concentrations by $59 \%$ and $52 \%$, respectively. Other omega- 6 FAs were also lowered by $\mathrm{KrO}$, with the exception of linoleic acid and gamma-linolenic acid. The concentrations of monosaturated, saturated and trans FAs were scarcely changed by $\mathrm{KrO}$.

Collectively, these data indicate that $\mathrm{KrO}$ treatment affected the lipid composition in the circulation, eWAT and the liver in a comparable way: all tissues showed a marked 
increase in omega-3 FAs and a decrease in ARA concentrations. The highest absolute concentrations of omega-3 FAs were observed in the liver.

\subsection{KrO Reduces WAT Inflammation, Improves Adipocyte Size Distribution and Increases Inflammation-Resolving Lipid Mediators Derived from EPA and DHA}

We next investigated the possible effects of $\mathrm{KrO}$ on WAT histology, and analyzed adipocyte cell size, WAT inflammation (CLS) and the total number of adipocytes in eWAT.

The average adipocyte cell size of the HFD control group $\left(5063.1 \pm 518.7 \mu \mathrm{m}^{2}\right)$ was similar to that of the chow reference group $\left(4724.4 \pm 891.1 \mu \mathrm{m}^{2}\right)$. Treatment with $\mathrm{KrO}$ significantly reduced the average adipocyte size $\left(4200.1 \pm 709.6 \mu \mathrm{m}^{2}\right)$ relative to HFD (Figure 1A,B). A subsequent, more refined, analysis of the cell size distribution revealed that this effect was attributable to an increase in the number of very small adipocytes $\left(<2000 \mu \mathrm{m}^{2}\right)$ by $\mathrm{KrO}$, whereas the number of large adipocytes $\left(>8000 \mu \mathrm{m}^{2}\right)$, which reportedly release many inflammatory mediators [33], decreased (Figure 1C).
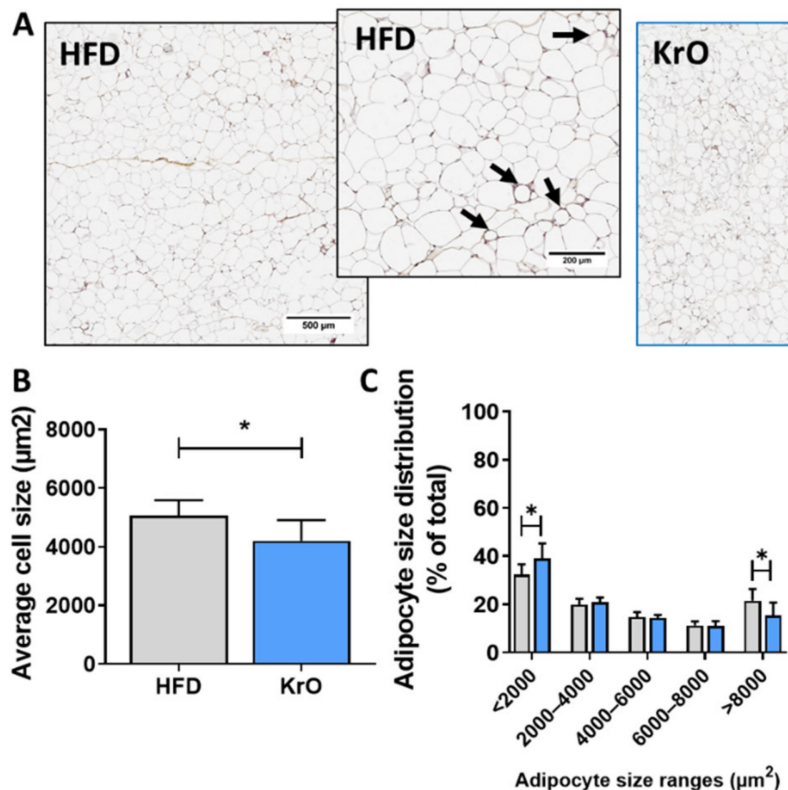

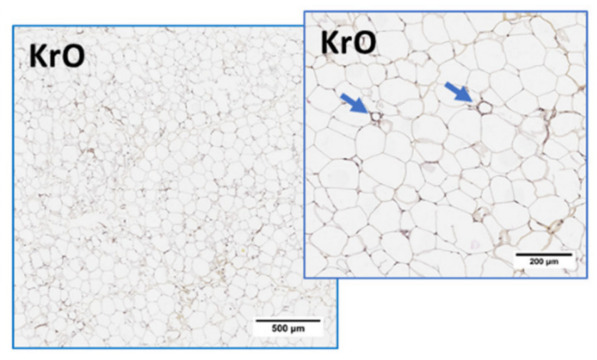

D

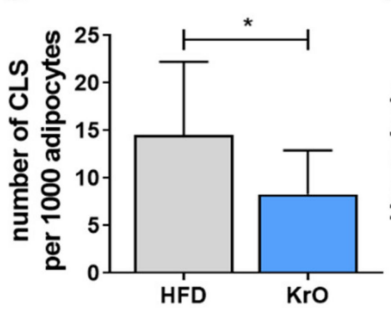

E

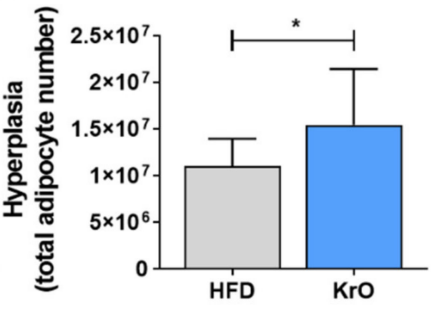

Figure 1. Effect of $\mathrm{KrO}$ on eWAT. (A) Representative images of HPS-stained eWAT, one low magnification image and one high magnification image per treatment, with arrows to indicate crown-like structures (CLS). eWAT sections were analyzed to determine (B) average adipocyte cell size, (C) adipocyte size distribution, (D) number of CLS per 1000 adipocytes, and

(E) total number of eWAT cells as a measure of hyperplasia. Data are presented as mean $\pm \mathrm{SD},{ }^{*} p<0.05$ compared to HFD.

In the HFD control group, many immune cells were observed, and a substantial portion of inflammatory cells formed CLSs ( $14.5 \pm 7.7$ per 1000 adipocytes). The number of CLSs in HFD was strongly increased relative to chow (2.2 \pm 4.8 CLSs per 1000 adipocytes). Treatment with $\mathrm{KrO}$ prevented HFD-induced CLS formation and significantly reduced CLS numbers by approximately $42 \%$ (Figure 1D), demonstrating that $\mathrm{KrO}$ reduces tissue inflammation. This histological effect was substantiated by the results of a genome-wide gene expression analysis and subsequent upstream regulator analysis of eWAT. This analysis predicts the activation state of an upstream regulator (e.g., cytokines, signaling molecules, transcription factors) based on the expression pattern of genes downstream from this regulator. HFD activated multiple upstream regulators relative to chow, including $\mathrm{TNF} \alpha$, TRAP1, CCL2/MCP-1, IL-1 $\beta$, IL-6 and MIF, indicating the activation of a broad spectrum of proinflammatory signaling pathways. $\mathrm{KrO}$ significantly suppressed many of these inflammatory pathways, as demonstrated by the deactivation of the respective upstream regulators/cytokines (Table 3). 
Table 3. Upstream regulator analysis in eWAT.

\begin{tabular}{|c|c|c|c|c|}
\hline & \multicolumn{2}{|c|}{ HFD vs. Chow } & \multicolumn{2}{|c|}{ KrO vs. HFD } \\
\hline & Z-Score & $p$-Value & Z-Score & $p$-Value \\
\hline \multicolumn{5}{|c|}{ Proinflammatory } \\
\hline CCL2 & 3.4 & 0.000 & -2.2 & 0.013 \\
\hline IL1B & 6.7 & 0.000 & -2.3 & 0.306 \\
\hline IL4 & 3.2 & 0.000 & -0.1 & 0.016 \\
\hline IL6 & 3.5 & 0.000 & -1.1 & 0.027 \\
\hline IL17A & 2.5 & 0.000 & -1.9 & 1.000 \\
\hline MIF & 4.2 & 0.000 & -1.9 & 1.000 \\
\hline TNF & 9.5 & 0.000 & -4.5 & 0.001 \\
\hline TRAP1 & 3.5 & 0.015 & -2.4 & 0.001 \\
\hline TGFB1 & 4.7 & 0.000 & -1.0 & 0.009 \\
\hline \multicolumn{5}{|c|}{ Adipogenesis-Clonal Expansion } \\
\hline AP1 & 3.3 & 0.001 & $\mathrm{n} / \mathrm{a}$ & 1.000 \\
\hline CEBPB & 1.7 & 0.000 & 1.4 & 0.004 \\
\hline CEBPD & 2.2 & 0.000 & $\mathrm{n} / \mathrm{a}$ & 1.000 \\
\hline \multicolumn{5}{|c|}{ Adipogenesis-Differentiation } \\
\hline PPARG & -4.9 & 0.000 & 5.0 & 0.000 \\
\hline RB1 & -6.5 & 0.000 & 5.1 & 0.000 \\
\hline CEBPA & 0.7 & 0.000 & 1.1 & 0.018 \\
\hline KLF4 & -1.1 & 0.004 & 2.0 & 1.000 \\
\hline KLF5 & -0.8 & 0.006 & $\mathrm{n} / \mathrm{a}$ & 1.000 \\
\hline KLF15 & $\mathrm{n} / \mathrm{a}$ & 1.000 & 3.0 & 0.000 \\
\hline SREBF1 & -1.5 & 0.000 & 1.3 & 0.002 \\
\hline STAT5A & -1.2 & 0.000 & 2.8 & 0.004 \\
\hline STAT5B & -0.7 & 0.000 & 2.1 & 0.427 \\
\hline \multicolumn{5}{|c|}{ Negative Regulators of Adipogenesis } \\
\hline KDM5A & 4.6 & 0.000 & -5.2 & 0.000 \\
\hline STK11 & 3.5 & 0.000 & -4.6 & 0.000 \\
\hline KLF2 & -1.2 & 0.000 & $\mathrm{n} / \mathrm{a}$ & 1.000 \\
\hline GATA3 & 1.0 & 0.000 & $\mathrm{n} / \mathrm{a}$ & 1.000 \\
\hline WNT5a & -0.5 & 0.000 & $\mathrm{n} / \mathrm{a}$ & 1.000 \\
\hline \multicolumn{5}{|c|}{ Metabolism-Related } \\
\hline PPARGC1A & -4.5 & 0.000 & 4.8 & 0.000 \\
\hline PPARGC1B & -2.6 & 0.018 & 2.6 & 0.001 \\
\hline ESRRA & -3.5 & 0.000 & 2.5 & 0.000 \\
\hline NRF1 & -0.7 & 0.031 & 2.2 & 0.003 \\
\hline INSR & -3.4 & 0.000 & 3.9 & 0.000 \\
\hline IGF1R & -2.6 & 0.000 & 3.4 & 0.056 \\
\hline IRS1 & -0.5 & 0.000 & 1.6 & 0.001 \\
\hline
\end{tabular}

The activity of upstream regulators in eWAT was calculated based on gene expression changes of all downstream target genes. A Z-score $<-2$ indicates inhibition of the respective pathway (shown in orange) and $Z>2$ indicates activation (shown in green). The $p$-value $<0.05$ indicates significant enrichment of the target genes downstream of a regulator, i.e., that more downstream genes are affected than can be expected by chance. $\mathrm{n} / \mathrm{a}$ indicates an insufficient number of differentially expressed genes to predict the activation state of an upstream regulator.

Intracellular free PUFAs and their respective oxylipin metabolites directly involved in regulating inflammatory responses were measured in eWAT homogenates. A schematic overview of oxylipins that can be synthesized from EPA, DHA and ARA is provided in Figure 2A, together with the tissue concentrations of these three precursors (Figure 2B). Feeding with the HFD lowered the levels of omega-3-derived mediators 13-HoTre and 19,20 DiHDPA and increased 18-HEPE and 4-HDHA, 10-HDHA and 17-HDHA (Table 4). Simultaneously, HFD increased intracellular ARA and many pro-inflammatory omega-6derived oxylipins, including 9-HoDE, 8-11- and 15-HETE and prostaglandin D2 (PGD 2$)$. By contrast, $\mathrm{KrO}$ upregulated all EPA- and DHA-derived oxylipins, whereas almost all omega- 6 derived pro-inflammatory oxylipins were significantly suppressed with the $\mathrm{KrO}$ $\operatorname{diet}$ (Table 4). 
A

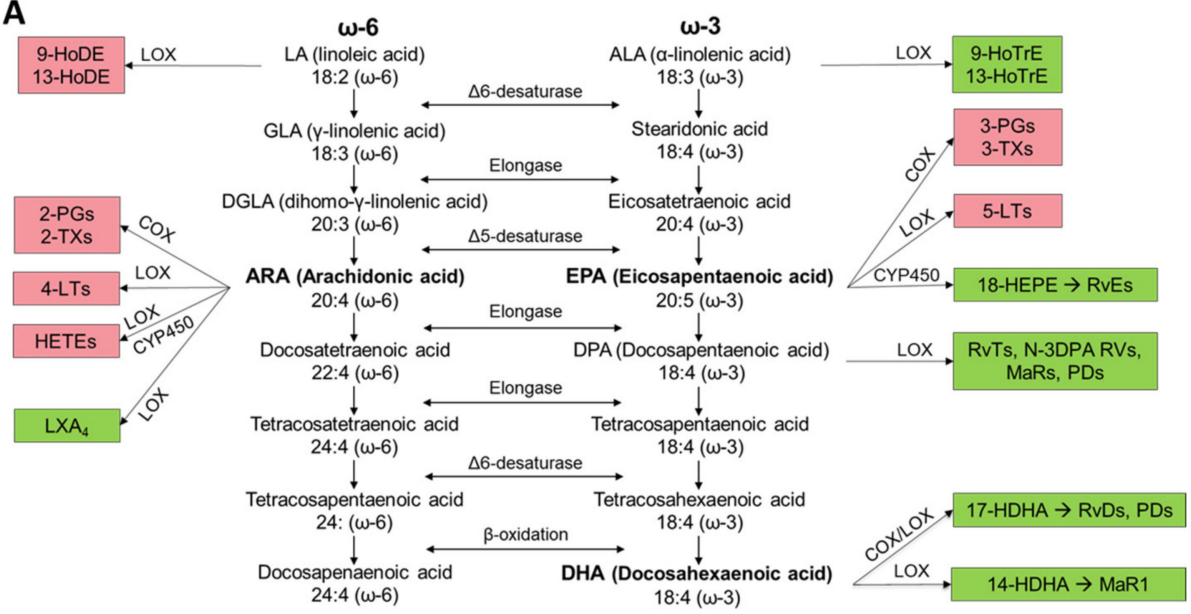

\section{B}
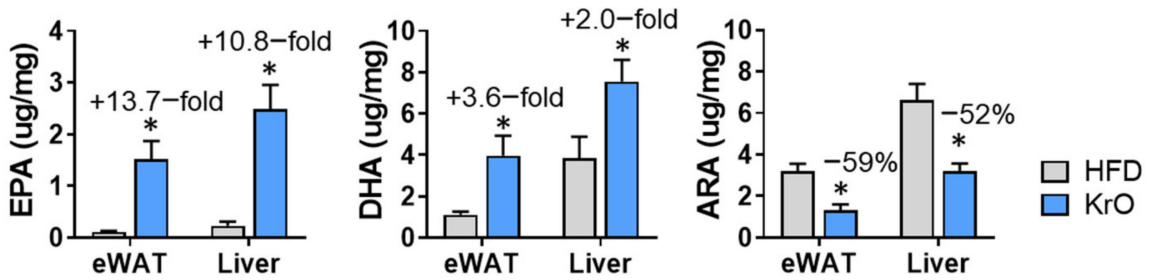

Figure 2. (A) Overview of omega-6 ( $\omega-6)$ and omega-3 ( $\omega-3)$ FA synthesis pathways with linoleic acid (LA) and $\alpha$-linolenic acid (ALA) constituting the upstream precursors, respectively. PUFAs compete for the same desaturase and elongase enzymes during the synthesis of eicosapentaenoic acid (EPA), docosahexaenoic acid (DHA) and arachidonic acid (ARA). These PUFAs can further be metabolized by the COX/LOX/CYP450 enzymes into oxylipins. Oxylipins that are typically implicated in the potentiation of inflammatory responses are highlighted in red, whereas oxylipins typically involved in the resolution of inflammatory responses are shown in green. (B) Effect of $\mathrm{KrO}$ on the tissue concentrations of EPA, DHA and ARA, determined by GC. Data are presented as mean $\pm \mathrm{SD}, * p<0.05$ compared to HFD.

Table 4. Oxylipin analysis in eWAT.

\begin{tabular}{cccc}
\hline & Chow & HFD & KrO \\
\hline Omega-3 Lipid Mediators & & & \\
ALA/GLA & 0.025 & 0.024 & 0.021 \\
9-HoTrE & $0.011 * 012$ \\
13-HoTrE & $0.027^{*}$ & 0.020 & 0.011 \\
EPA & 0.005 & 0.017 & $0.074^{*}$ \\
5-HEPE & $0.001^{*}$ & 0.010 & $0.011^{*}$ \\
12-HEPE & 0.012 & 0.001 & $0.067^{*}$ \\
15-HEPE & 0.003 & 0.017 & $0.026^{*}$ \\
18-HEPE & $0.002^{*}$ & 0.005 & $0.029^{*}$ \\
RvE2 & $\mathrm{ND}$ & 0.005 & $\mathrm{ND}$ \\
18R-RvE3 & 0.002 & $\mathrm{ND}$ & $\mathrm{ND}$ \\
DPAn-3 & 0.003 & $\mathrm{ND}$ & $0.018^{*}$ \\
DHA & 0.019 & 0.006 & $0.099^{*}$ \\
4-HDHA & $0.000^{*}$ & 0.042 & $0.003^{*}$ \\
7-HDHA & 0.001 & 0.002 & $0.004^{*}$ \\
10-HDHA & $0.001^{*}$ & 0.002 & $0.016^{*}$ \\
17-HDHA & $0.002^{*}$ & 0.007 & $0.013^{*}$ \\
PDX & 0.001 & 0.007 & $0.004^{*}$ \\
14,15-diHETE & $\mathrm{ND}$ & 0.002 & 0.004 \\
14(S)-HDHA & 0.007 & 0.002 & $0.024^{*}$ \\
19-DiHDPA & $0.013^{*}$ & 0.013 & $0.015^{*}$ \\
\hline
\end{tabular}


Table 4. Cont.

\begin{tabular}{|c|c|c|c|}
\hline & Chow & HFD & $\mathrm{KrO}$ \\
\hline \multicolumn{4}{|l|}{ Omega-6 Lipid Mediators } \\
\hline LA & 0.059 & 0.060 & 0.074 \\
\hline 9-HoDE & $0.269 *$ & 0.662 & $0.362 *$ \\
\hline 13-HoDE & 0.506 & 0.959 & 0.569 * \\
\hline DGLA & 0.003 * & 0.006 & 0.006 \\
\hline ARA & $0.015^{*}$ & 0.046 & $0.018^{*}$ \\
\hline 5-HETE & 0.005 * & 0.028 & $0.006^{*}$ \\
\hline LXA4 & 0.001 & 0.002 & ND \\
\hline 5-KETE & $0.002 *$ & 0.011 & $0.003 *$ \\
\hline 8-HETE & $0.005 *$ & 0.042 & $0.008 *$ \\
\hline 11-HETE & 0.030 * & 0.290 & 0.051 * \\
\hline 12-HETE & 0.065 & 0.247 & $0.046^{*}$ \\
\hline 12-KETE & 0.003 & 0.006 & 0.002 \\
\hline 15-HETE & $0.015^{*}$ & 0.111 & 0.024 * \\
\hline 15-KETE & $0.003 *$ & 0.016 & $0.005 *$ \\
\hline 8S,15S-diHETE & 0.001 & 0.002 & 0.000 * \\
\hline 17-OH-DH-HETE & $0.001 *$ & 0.005 & $0.001 *$ \\
\hline $\mathrm{PGD}_{2}$ & $0.042 *$ & 0.311 & 0.028 * \\
\hline $\mathrm{PGE}_{2}$ & 0.057 & 1.226 & $0.052 *$ \\
\hline $\mathrm{PGF}_{2 \alpha}$ & 0.006 & 0.034 & 0.004 * \\
\hline $\mathrm{PGJ}_{2}$ & ND & 0.017 & ND \\
\hline 8-iso- PGF $_{2 \alpha}$ & $0.001 *$ & 0.003 & $0.001 *$ \\
\hline 13,14 dihydro-15 keto- PGF $_{2 \alpha}$ & ND & 0.009 & ND \\
\hline $\mathrm{TxB}_{2}$ & 0.012 & 0.051 & $0.005^{*}$ \\
\hline 6-tra-LTB 4 & 0.001 & 0.003 & 0.001 \\
\hline $6 \mathrm{t}, 12$ epi-LTB 4 & 0.001 & 0.004 & 0.001 \\
\hline AdA & $0.001 *$ & 0.004 & 0.001 * \\
\hline DPAn-6 & 0.002 * & 0.011 & $0.002 *$ \\
\hline
\end{tabular}

Lipid mediator levels (area ratios relative to the class-specific internal standard) measured in eWAT tissue are expressed as mean area ratios. Area ratios significantly higher compared to the HFD control group are shown in orange, and significantly lower ratios are shown in green $\left({ }^{*} p<0.05\right)$. In the left column, data from the chow group are provided for reference. $\mathrm{ND}=$ not detectable.

Pathway analysis of the gene expression data also revealed that apelin signaling, an insulin-dependent adipocyte differentiation pathway [34], was strongly activated by $\mathrm{KrO}$ and that the activity of important upstream regulators of adipogenesis, including PPAR $\gamma$, RB1, CEBP $\alpha$, KL4, KL15, STAT5A and STAT5B (Table 3), was stimulated by KrO. Conversely, negative regulators of differentiation, such as KDM5A and STK11, were activated by HFD and suppressed with $\mathrm{KrO}$. To corroborate this finding with histology results, we calculated the total number of adipocytes present in eWAT using an established method [28]. The adipocyte number in eWAT of HFD-fed animals $\left(1.10 \times 10^{7}\right)$ was similar to that of the chow reference group $\left(1.08 \times 10^{7}\right)$. Interestingly, $\mathrm{KrO}$-fed mice showed a significant 1.4 -fold increase in adipocyte numbers $\left(1.54 \times 10^{7}\right)$, which is clearly indicative of hyperplasia (Figure 1E) and which supports the results of the upstream regulator analysis.

Furthermore, HFD deactivated PPARGC1A, PPARGC1B, ESRRA and NRF1, whereas $\mathrm{KrO}$ strongly induced these upstream regulators, pointing to a beneficial effect on mitochondrial biogenesis.

Collectively, these data show that treatment with $\mathrm{KrO}$ reduced CLSs and increased the number of adipocytes in eWAT. In line with these histological results, $\mathrm{KrO}$ prevented the activation of inflammatory regulators by HFD, increased PUFA concentrations and stimulated the formation of anti-inflammatory bioactive lipids. KrO treatment also resulted in a shift towards smaller adipocytes and fewer large adipocytes, possibly as a consequence of its adipogenesis-stimulating effect. 


\subsection{Effect of $\mathrm{KrO}$ on Adipokines and Metabolic Risk Factors}

We next investigated whether the observed histological changes in WAT were accompanied by effects on adipokine levels and insulin resistance (HOMA-IR).

Plasma leptin levels were $2.5 \pm 2.0 \mathrm{ng} / \mathrm{mL}$ at $\mathrm{t}=0$ and were increased by HFD, reaching $58.1 \pm 10.8 \mathrm{ng} / \mathrm{mL}$ in week 28 , which differed significantly from the chow reference group $(26.6 \pm 8.0 \mathrm{ng} / \mathrm{mL})$. KrO significantly attenuated this HFD-evoked increase in leptin $(37.7 \pm 6.4 \mathrm{ng} / \mathrm{mL})$. Furthermore, the total leptin exposure over time (AUC from data at 0 , 8,16 and 28 weeks) was significantly reduced by $\mathrm{KrO}$ (Table 5). Plasma adiponectin levels were higher with $\mathrm{KrO}$ compared to HFD at the beginning of the treatment until week 16 and this difference became smaller towards the end of the study. The total adiponectin exposure over time (AUC) was significantly higher in $\mathrm{KrO}$ compared to HFD (Table 5).

Table 5. Effect of $\mathrm{KrO}$ on adipokines, metabolic risk factors and transaminases.

\begin{tabular}{cccc}
\hline & Chow & HFD & KrO \\
\hline AUC leptin & $32.3 \pm 16.4^{*}$ & $114.2 \pm 15.4$ & $100.4 \pm 0.4^{*}$ \\
AUC adiponectin & $18.5 \pm 1.8^{*}$ & $22.5 \pm 2.5$ & $25.19 \pm 2.3^{*}$ \\
Glucose (mM) & $7.2 \pm 0.8$ & $7.6 \pm 0.9$ & $6.9 \pm 0.9^{*}$ \\
Insulin (ng/mL) & $4.1 \pm 3.9^{*}$ & $20.4 \pm 14.4$ & $12.4 \pm 7.1^{*}$ \\
HOMA-IR & $34.1 \pm 33.9^{*}$ & $170.2 \pm 116.3$ & $92.2 \pm 46.8^{*}$ \\
Free fatty acids (mM) & $1.1 \pm 0.2$ & $1.3 \pm 0.4$ & $2.4 \pm 1.0^{*}$ \\
ALT (U/l) & $66.6 \pm 21.5^{*}$ & $391.9 \pm 258.2$ & $277.9 \pm 170.7$ \\
AST (U/l) & $17.8 \pm 3.9^{*}$ & $491.1 \pm 497.2$ & $264.2 \pm 104.1$ \\
\hline
\end{tabular}

AUC: area under the curve, HOMA-IR: homeostatic model assessment for insulin resistance, ALT: alanine aminotransferase, AST: aspartate aminotransferase. In the left column, data from the chow group are shown for reference. Data are presented as mean $\pm \mathrm{SD},{ }^{*} p<0.05$ compared to HFD.

Fasting blood glucose levels and HFD-induced increases in plasma insulin levels were reduced with $\mathrm{KrO}$. Subsequently, the HOMA-IR values were significantly lower in the $\mathrm{KrO}$ group, indicating that $\mathrm{KrO}$ improved insulin resistance. Genome-wide gene expression analysis showed that HFD inactivated upstream regulators that are important in insulin signaling (INSR and IGF1R) in both the liver and eWAT, and KrO counteracted this effect in eWAT (Table 3).

Free fatty acid (FFA) plasma concentrations were not significantly raised with HFD, whereas $\mathrm{KrO}$ significantly increased FFAs compared to the HFD in line with the lower insulin concentrations.

Plasma ALT and AST levels were significantly increased by the HFD compared to the chow reference diet. This increase in both ALT and AST tended to be less pronounced in the $\mathrm{KrO}$ group.

Taken together, $\mathrm{KrO}$ reduced leptins and increased adiponectin exposure, which was paralleled by an improvement in HOMA-IR.

\subsection{Effects of Krill Oil in the Liver}

HFD treatment resulted in the development of hepatic steatosis, hepatocellular hypertrophy and the formation of F4/80-positive CLSs, indicating macrophage aggregation around dying hepatocytes (Figure 3A-D). These histological characteristics were practically absent in the chow group. The liver histology and the lipid content of the $\mathrm{KrO}$ group was comparable to that of the HFD group. On a molecular level, however, gene expression profiling and subsequent upstream regulator analysis demonstrated the activation of many proinflammatory pathways by HFD, which were reversed by $\mathrm{KrO}$ (Table 6). More specifically, $\mathrm{KrO}$ quenched the HFD-induced activation of proinflammatory cytokine signaling (e.g., by IL-1 $\beta$, IFN-A2 and CSF1) and proinflammatory transcription factors (e.g., REL-A/p65-NF- $\mathrm{kB}$ and STAT1). Critical upstream regulators of metabolism, including the $\beta$-oxidation enzyme ACOX 1 and the mitochondrial biogenesis activator PPARGC1A, were deactivated with $\mathrm{HFD}$, and $\mathrm{KrO}$ attenuated this effect, suggesting a reactivation of lipid processing. Moreover, HFD activated SREBF1 as key regulator of de novo lipogenesis, 
whereas KrO deactivated SREBF1 and thereby seemed to suppress lipid synthesis. Furthermore, cholesterol synthesis regulators deactivated by HFD (e.g., SCAP, SREBP2) were even further suppressed with $\mathrm{KrO}$ (Table 6).
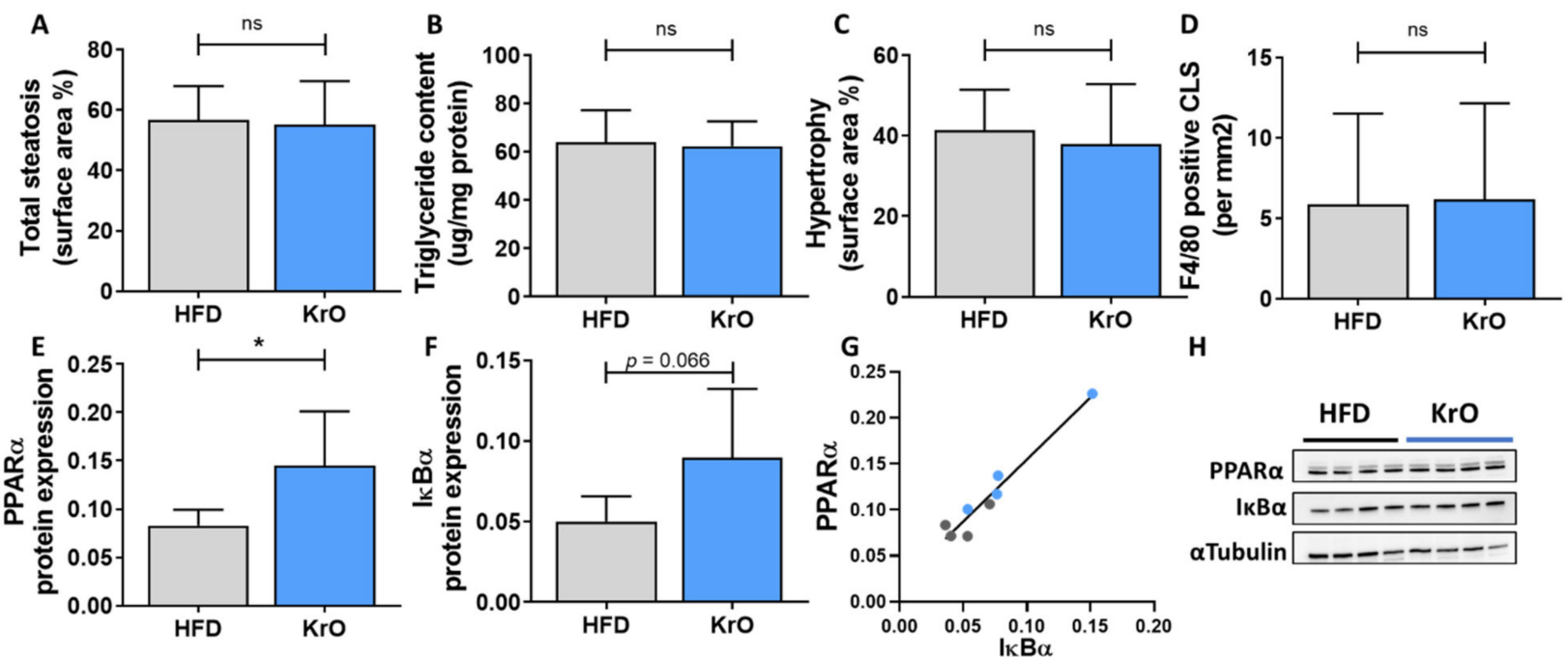

H

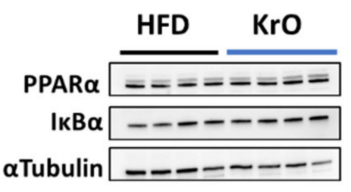

Figure 3. Effect of $\mathrm{KrO}$ on the liver-(A) total steatosis, (B) triglyceride content expressed per mg of liver protein (C) hepatocellular hypertrophy and (D) F4/80-positive crown-like structures (CLSs). Liver protein levels of (E) PPAR $\alpha$ and (F) IKB $\alpha$ normalized for $\alpha$ Tubulin expression, and $(\mathbf{G})$ correlation between PPAR $\alpha$ and IKB $\alpha$. (H) representative images of the Western blot bands. Data are presented as mean $\pm \mathrm{SD},{ }^{*} p<0.05$ compared to HFD.

Table 6. Upstream regulator analysis in the liver.

\begin{tabular}{ccccc}
\hline & \multicolumn{2}{c}{ HFD vs. Chow } & \multicolumn{2}{c}{ KrO vs. HFD } \\
Proinflammatory & Z-Score & $p$-Value & Z-Score & $p$-Value \\
\hline CCL2 & 1.8 & 0.000 & -2.0 & 0.171 \\
CXCL12 & 4.2 & 0.000 & -0.3 & 0.011 \\
IL1B & 7.9 & 0.000 & -2.1 & 0.001 \\
IFNA2 & 4.7 & 0.002 & -1.9 & 0.036 \\
IFNB1 & 2.7 & 0.000 & -0.5 & 0.006 \\
IFNG & 6.1 & 0.000 & -0.6 & 0.001 \\
CSF1 & 5.1 & 0.000 & -3.2 & 0.000 \\
TNF & 9.7 & 0.000 & -1.1 & 0.000 \\
NFKB1 & 4.8 & 0.000 & -1.3 & 0.042 \\
NFKBIA & 3.2 & 0.000 & 0.2 & 0.029 \\
RELA & 4.9 & 0.000 & -1.5 & 0.006 \\
REL & 3.2 & 0.000 & -2.0 & 0.074 \\
STAT1 & 6.4 & 0.000 & -1.7 & 0.000 \\
TICAM1 & 4.8 & 0.000 & -2.6 & 0.068 \\
\hline Metabolism-Related & & & & 0.000 \\
\hline ACOX1 & -5.4 & 0.000 & 1.7 & 0.004 \\
PPARGC1A & -2.7 & 0.000 & 1.7 & 0.000 \\
SCAP & -3.2 & 0.000 & -3.8 & 0.000 \\
SREBF1 & 1.0 & 0.000 & -2.6 & 0.000 \\
SREBF2 & -1.7 & 0.001 & -3.2 & \\
\hline
\end{tabular}

The activity of an upstream regulator in the liver was calculated based on gene expression changes of all downstream target genes. A Z-score $<-2$ indicates inhibition of the respective pathway (shown in orange) and $Z>2$ indicates activation (shown in green). The $p$-value $<0.05$ indicates significant enrichment of the target genes downstream of a regulator, i.e., that more downstream genes are affected than can be expected by chance. $\mathrm{n} / \mathrm{a}$ indicates an insufficient number of differentially expressed genes to predict the activation state of an upstream regulator.

When compared to its anti-inflammatory activities in WAT, KrO attenuated different pro-inflammatory pathways and a different set of transcriptional regulators in the liver. 
Many of the KrO-modulated signaling pathways in the liver converge in transcriptional regulation by NF- $\mathrm{kB}$ family members, and KrO significantly deactivated REL-A/p65-NF$\kappa \mathrm{B}$, for instance. In line with this, Western blot analysis of liver tissue homogenates revealed an increase in PPAR $\alpha$ protein expression and a trend $(p=0.066)$ towards an increase in $\mathrm{I} \kappa \mathrm{B} \alpha$ protein levals by $\mathrm{KrO}$ relative to HFD. PPAR $\alpha$ protein expression was significantly correlated with $I_{\kappa} B \alpha$ protein expression $\left(R^{2}=0.9\right)$ (Figure 3D-F).

Next, we investigated whether $\mathrm{KrO}$ affected the intrahepatic levels of bioactive lipids using the same oxylipin platform as before. Table 7 shows that HFD significantly decreased the levels of ALA-, EPA- and DHA-derived lipid mediators (e.g., 15- and 18-HEPE, involved in inflammation resolution), while increasing many LA- and ARA-derived lipid species known to promote inflammation (e.g., HETEs, $\mathrm{PGD}_{2}, \mathrm{PGE}_{2}, \mathrm{PGF}_{2}$ and $\mathrm{TXB}_{2}$ ). By contrast, KrO-treated livers exhibited lower levels of ALA and higher levels of LA, suggesting that the processing of omega-3 FAs is enhanced in the presence of $\mathrm{KrO}$. Indeed, all detectable EPA- and DHA-derived metabolites (except 14-HDHA, a precursor of $\mathrm{MaR}_{1}$ ) were significantly increased with $\mathrm{KrO}$ and a strong signal corresponding to genuine resolvin $\mathrm{RvE}_{2}$ (same MS/MS transition, identical retention time) was only detectable in $\mathrm{KrO}$-fed mice. Strikingly, $\mathrm{KrO}$ suppressed the formation of oxylipins with proinflammatory properties downstream of ARA to such an extent that they were no longer detectable.

Table 7. Oxylipin analysis in the liver.

\begin{tabular}{|c|c|c|c|}
\hline & Chow & HFD & $\mathrm{KrO}$ \\
\hline \multicolumn{4}{|l|}{ Omega-3-Derived } \\
\hline ALA/GLA & $0.208 *$ & 0.304 & 0.143 * \\
\hline 9-HoTrE & $0.070 *$ & 0.016 & 0.022 * \\
\hline 13-HoTrE & $0.036 *$ & 0.015 & 0.013 \\
\hline EPA & 0.283 & 0.267 & 1.765 * \\
\hline 5-HEPE & $0.033 *$ & 0.007 & 0.096 * \\
\hline 12-HEPE & $0.559 *$ & 0.172 & $1.077^{*}$ \\
\hline 15-HEPE & $0.029 *$ & 0.011 & 0.126 * \\
\hline 18-HEPE & $0.052 *$ & 0.012 & 0.169 * \\
\hline $\mathrm{RvE}_{2}$ & ND & ND & 0.004 \\
\hline $18 \mathrm{R}-\mathrm{RvE}_{3}$ & ND & ND & ND \\
\hline DPAn-3 & $0.110 *$ & 0.157 & 0.525 * \\
\hline DHA & $0.858 *$ & 1.419 & 2.920 * \\
\hline 4-HDHA & $0.037 *$ & 0.015 & 0.039 \\
\hline 7-HDHA & 0.014 & 0.010 & $0.027^{*}$ \\
\hline 10-HDHA & 0.066 & 0.049 & 0.122 * \\
\hline 17-HDHA & 0.052 & 0.044 & 0.074 * \\
\hline PDX & 0.013 & 0.014 & 0.027 * \\
\hline 14,15-diHETE & $0.062 *$ & 0.028 & $0.206^{*}$ \\
\hline 14(S)-HDHA & 0.123 & 0.126 & 0.155 \\
\hline 19,20-DiHDPA & $0.303 *$ & 0.517 & 0.643 * \\
\hline \multicolumn{4}{|l|}{ Omega-6-Derived } \\
\hline LA & 0.296 & 0.339 & 0.420 * \\
\hline 9-HoDE & $1.567 *$ & 0.935 & 0.746 \\
\hline 13-HoDE & $2.399 *$ & 1.367 & 1.167 \\
\hline DGLA & $0.095 *$ & 0.189 & 0.215 \\
\hline ARA & $0.372 *$ & 0.658 & 0.348 * \\
\hline 5-HETE & $0.150 *$ & 0.083 & $0.037 *$ \\
\hline $\mathrm{LXA}_{4}$ & 0.008 & 0.015 & 0.004 \\
\hline 8-HETE & 0.070 & 0.069 & 0.032 * \\
\hline 11-HETE & 0.555 & 0.675 & 0.222 * \\
\hline 12-HETE & 1.146 & 1.255 & 0.308 * \\
\hline 15-HETE & 0.491 & 0.418 & 0.172 * \\
\hline 15-KETE & 0.045 & 0.030 & 0.016 * \\
\hline
\end{tabular}


Table 7. Cont.

\begin{tabular}{cccc}
\hline & Chow & HFD & KrO \\
\hline 8S,15S-diHETE & 0.005 & 0.006 & $0.002^{*}$ \\
17-OH-DH-HETE & 0.016 & 0.019 & $0.004^{*}$ \\
PGD $_{2}$ & $0.039^{*}$ & 0.105 & $0.016^{*}$ \\
PGE $_{2}$ & 0.068 & 0.103 & $0.023^{*}$ \\
PGF $_{2 \alpha}$ & $0.041^{*}$ & 0.095 & $0.012^{*}$ \\
PGJ $_{2}$ & $\mathrm{ND}$ & $\mathrm{ND}$ & $\mathrm{ND}$ \\
8-iso- PGF $_{2 \alpha}$ & 0.003 & 0.004 & 0.002 \\
13,14 dihydro-15 keto- & $\mathrm{ND}$ & 0.005 & $\mathrm{ND}$ \\
PGF $_{2 \alpha}$ & $0.049^{*}$ & 0.133 & $0.017^{*}$ \\
TxB $_{2}$ & 0.004 & 0.003 & $\mathrm{ND}$ \\
6-tra-LTB & 0.006 & 0.004 & $\mathrm{ND}$ \\
6t,12epi-LTB & $0.028^{*}$ & 0.323 & $0.039^{*}$ \\
AdA & $0.073 *$ & $0.047^{*}$ \\
DPAn-6 & & & \\
\hline
\end{tabular}

Lipid mediator levels measured in liver tissue are expressed as mean area ratios. Area ratios significantly higher compared to the HFD control group are shown in orange, and ratios that are significantly lower are depicted in green $\left({ }^{*} p<0.05\right)$. In the left column, data from the chow group are provided for reference. ND $=$ not detectable.

Altogether, $\mathrm{KrO}$ quenched inflammatory signaling pathways and upregulated the expression of proteins that can interfere with NF-KB signaling (e.g., PPAR $\alpha$ ). It also suppressed the accumulation of lipids and oxylipins with pro-inflammatory properties and strongly induced the presence of lipid species that contribute to an anti-inflammatory milieu.

\section{Discussion}

This study shows that the fatty acid and oxylipin content of adipose tissue and the liver can be strongly modulated with $\mathrm{KrO}$ during the development of obesity, and that $\mathrm{KrO}$ treatment attenuates inflammatory processes, resulting in a reduced inflammatory tone. Lipidomic analyses, in conjunction with functional regulator analyses of signaling pathways in adipose tissue and the liver, provided rationales for possible direct and indirect mechanisms by which $\mathrm{KrO}$ exerts its effects. One of the direct effects is the increase in anti-inflammatory oxylipins. An important indirect effect is the activation of adipogenic gene expression programs in adipose tissue, accompanied by WAT hyperplasia. The observed increase in WAT storage capacity and the associated decrease in inflammation can contribute to whole-body metabolic health, which is consistent with the observed improvement in insulin resistance (i.e., HOMA-IR) and adipokine concentrations.

A general FA compositional analysis revealed that $\mathrm{KrO}$ strongly increased the omega-3 PUFA content in the circulation, WAT and the liver (especially that of EPA and DHA), while simultaneously decreasing the omega-6 PUFA content in these organs, with pronounced reductions in ARA. The observed fatty acid composition changes were grosso modo comparable for both organs, yet the absolute omega-3 PUFA concentrations per milligram of tissue were clearly higher in the liver. Importantly, a refined oxylipin LC-MS/MS analysis showed that $\mathrm{KrO}$ strongly increased lipid species with anti-inflammatory properties [35-37] derived from EPA and DHA (e.g., 18-HEPE, RvE 2, 14-HDHA, 17-HDHA, PDX/10S,17S-diHDHA), whereas it suppressed the HFD-induced formation of ARA-derived oxylipins (e.g., HETEs, $\mathrm{PGD}_{2}, \mathrm{PGE}_{2}, \mathrm{PGF}_{2}$ and $\mathrm{TXB}_{2}$ ), which often exert pro-inflammatory effects [37-41]. Notably, the results of the two independent lipidomics approaches employed herein (the fatty acid composition analysis and the oxylipin analyses) were in line with each other. Both approaches consistently indicated that $\mathrm{KrO}$ treatment altered the organ lipid environment in favor of PUFAs and oxylipins that can resolve inflammation, while lowering ARA and ARA-derived oxylipins that can promote inflammation. For instance, HFD-feeding increased $\mathrm{PGD}_{2}, \mathrm{PGE}_{2}$ and $\mathrm{PGF}_{2}$ levels in both WAT and the liver, which can stimulate chemotaxis of immune cells [42,43] by increasing local cytokine release and the endothelial expression of adhesion molecules to facilitate immune cell tissue infiltration [38,44]. $\mathrm{KrO}$ blunted this HFD-evoked effect, and the observed $\mathrm{PGD}_{2}, \mathrm{PGE}_{2}$ and $\mathrm{PGF}_{2}$ levels were even 
lower with $\mathrm{KrO}$ compared to the chow diet. Conversely, HFD feeding diminished the levels of anti-inflammatory oxylipins such as 18-HEPE, a precursor for E series resolvins, and 17-HDHA in liver [36]. KrO counteracted this detrimental effect, resulting in an increase of 18-HEPE and 17-HDHA levels in WAT and the liver. Notably, 17-HDHA treatment has been shown to reduce WAT inflammation, increase adiponectin expression and improve glucose tolerance in obese mice [36]. 18-HEPE, $\mathrm{RvE}_{2}, 14-\mathrm{HDHA}, 17-\mathrm{HDHA}, \mathrm{PDX}$ and other anti-inflammatory oxylipins were increased with $\mathrm{KrO}$ in this study and are thought to be directly involved in inflammation resolution mechanisms, as reported by [35-37,45-48], and hence may contribute to a lipid environment in WAT and the liver that protects against chronic inflammation.

It is likely that inflammation-resolving oxylipins were formed from their precursor fatty acids present in $\mathrm{KrO}$ (EPA and DHA), but these precursors themselves can also be enzymatically synthesized from ALA. The enzymes responsible for omega-3 PUFA processing are the same as those for omega- 6 processing but the rate-limiting enzyme, delta6-desaturase, has a higher preference for omega-3 FAs relative to omega-6 FAs $[49,50]$. Thus, an enhanced conversion of ALA in the presence of $\mathrm{KrO}$ may also explain the pronounced increases in anti-inflammatory oxylipins.

The observation that the levels of most PUFAs and oxylipins are higher in the liver than in WAT is consistent with metabolic studies in mice [51]. These tissue differences may have multiple causes, including the expression or activity of the aforementioned enzymes that ultimately determine the extent to which substrates (EPA, DHA, ARA) are available for subsequent enzymatic conversions (e.g., by Cyp450, COX, LOX and auto-oxidation) into the respective oxylipins [41,52]. Collectively, the lipidomic analyses demonstrate that $\mathrm{KrO}$ can directly affect the inflammatory milieu in WAT and the liver by modulating PUFA and oxylipins in these organs, suggesting beneficial effects on inflammatory pathways and processes.

Indeed, pathway and upstream regulator analyses clearly demonstrated a suppression of HFD-induced inflammatory pathways by $\mathrm{KrO}$ in WAT and the liver. For example, $\mathrm{KrO}$ deactivated multiple inflammatory HFD-stimulated pathways, including those controlled by TNF $\alpha$, TNF receptor-associated protein 1 (TRAP1) and CCL2 in eWAT, as well as the IL-

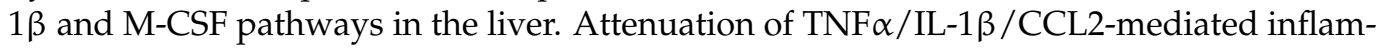
mation in metabolic organs has been shown to improve insulin resistance [53-55], consistent with the observed reduction of fasting insulin and HOMA-IR in KrO-treated mice. For instance, $\mathrm{TNF} \alpha$ inhibits insulin signaling by stimulating the phosphorylation of inhibitory residues on the insulin receptor substrates (IRS1 and IRS2) and impairs IRS-mediated phosphatidylinositol 3-kinase activation [56,57]. KrO appeared to interfere with this process in our study, because we observed significantly increased upstream regulator activities of INSR, IGF1R and IRS1 in eWAT. This effect is consistent with reduced CLS counts in eWAT and was paralleled by decreased leptin and increased adiponectin concentrations in plasma. The KrO-dependent adipokine changes point to an improvement in whole-body homeostasis, including the neuroendocrine circuits affecting adipocytes [58]. Observed elevations in adiponectin can directly affect immune cells, mediating anti-inflammatory activities [59], as well as affecting general metabolism by inhibiting gluconeogenesis and stimulating lipid utilization/b-oxidation $[60,61]$, which is consistent with our pathway analyses.

The deactivation of TRAP1 by KrO points to reduced oxidative-inflammatory stress in eWAT because TRAP1 is a mitochondrial heat shock protein involved in the maintenance of mitochondrial integrity under stress or pathological conditions [62].

In addition, KrO stimulated the activity of PPAR $\gamma, \mathrm{RB} 1, \mathrm{CEBP} \alpha, \mathrm{KLF} 15$ and STAT5A, all of which are transcriptional master regulators that orchestrate adipogenesis $[63,64]$, and it suppressed negative regulators of adipogenesis (KDM5A and STK11). Consistently with the $\mathrm{KrO}$-induced proadipogenic gene expression program in eWAT, the absolute number of adipocytes increased in this depot, and so did the proportion of small adipocytes, together indicating $\mathrm{KrO}$-induced hyperplasia. WAT hyperplasia constitutes a mechanism by which the total storage capacity for fat is increased, allowing the body to cope with metabolic 
overload from HFD [3]. This indirectly prevents adipocyte hypertrophy and tissue inflammation and attenuates the effect of cytokines implicated in insulin resistance (e.g., TNF $\alpha$ and MIF signaling [4]), as observed herein. Furthermore, $\mathrm{KrO}$ also activated PGC1A, PGC1B, ESSRA and NRF1, which are indicative of increased mitochondrial biogenesis (growth and division of pre-existing mitochondria) in eWAT, which is in line with the reported effects of PUFAs during adipocyte differentiation $[65,66]$. The activation of PPAR $\gamma$ by KrO-derived lipids may, at least partly, explain the effects observed in eWAT, as well as the observed increase in adiponectin, a PPAR $\gamma$ target gene [59,67]. PPAR $\gamma$ activation could also be responsible for the decrease in leptin, because PPAR $\gamma$ antagonizes CEBP $\alpha$-mediated leptin mRNA transcription [68]. The activation of PPAR $\gamma$ and PPAR $\alpha$ by PUFAs and oxylipins from $\mathrm{KrO}$ may contribute to the anti-inflammatory effects observed in WAT and the liver. Activated PPARs can negatively interfere with proinflammatory transcription factors such as NF- $\mathrm{KB}$ in several ways: PPARs can directly interact with NF- $\mathrm{KB}$ proteins [69] or increase the cytosolic inhibitor, I $\kappa B \alpha$, thereby preventing nuclear translocation and NF-kB-mediated gene expression $[10,11]$. The observed increase in PPAR $\alpha$ protein levels and high concentrations of potential ligands in KrO-treated livers support the possibility of anti-inflammatory mechanisms involving direct PPAR $\alpha$ interaction, [69] and complementary indirect mechanisms (e.g., an increase in $\mathrm{I} \kappa \mathrm{B} \alpha$ ) that negatively interferes with NF- $\kappa \mathrm{B}$ signaling. Although $\mathrm{KrO}$ attenuated CLS formation in eWAT, there was no effect on F4/80positive CLSs in the liver. This may be explained by a fundamental difference in plasticity between these organs: although the WAT can respond with hyperplasia and expand further (or redistribute fat among its depots) [70], the liver is anatomically restricted, with a limited storage capacity so that even lipids that are beneficial in nature may cause physical damage to cells when present in excess amounts. In addition, the higher circulating FFAs with $\mathrm{KrO}$ may result in a higher influx of fat to the liver, thereby counteracting the beneficial effects on hepatic fat oxidation (i.e., PPARA, ACOX1, PPARGC1A), altogether leading to comparable hepatic steatosis as in the HFD controls. Of note, the steatosis observed in the $\mathrm{KrO}$ group is unlikely to be a consequence of increased de novo lipogenesis, because $\mathrm{KrO}$ significantly suppressed SREBF1 activity-the key regulator of hepatic lipid synthesis. This is also in line with the observed reduced fasting insulin concentrations with $\mathrm{KrO}$. By contrast, at least a part of the steatosis observed in the HFD control group may be due to increased de novo lipogenesis because SREBF1 is significantly activated, and insulin, the transcriptional inducer of Srebp1c, is elevated.

This study has limitations and strengths. Intrinsic to the set-up of the study, we cannot distinguish whether the replacement of $\mathrm{HFD}$ by $\mathrm{KrO}$ per se, or specific $\mathrm{KrO}$ components or metabolites formed from $\mathrm{KrO}$, or a combination of the above, are responsible for the beneficial effects observed in KrO-treated mice. We could have included additional groups to substantiate these findings, for instance, groups in which $\mathrm{KrO}$ was administered orally superimposed on the HFD. Another limitation is that we cannot estimate the contribution of the PUFAs attached to phospholipids relative to those in other lipid classes. It is possible that the profound effects of $\mathrm{KrO}$ are related to its high phospholipid content and the increased bioavailability of EPA and DHA [71], which consequently also affects oxylipin availability. Important strengths of this study are the long period of $\mathrm{KrO}$ treatment (28 weeks), resulting in relevant endpoints; the use of large treatment groups ( $n=15$ mice) for high statistical power; the extensive molecular (omics) analyses of adipose tissue and the liver using next-generation sequencing technology to identify activated pathways and upstream regulators in both organs; the profiling of fatty acids in three compartments (plasma, adipose tissue, liver), which provides information on the relative enrichment of PUFAs in each of these tissues; and one of the most comprehensive oxylipin analysis reported so far, including adipose tissue and the liver. Our oxylipin profiling analyses at the tissue level showed that HFD treatment markedly increased oxylipins with proinflammatory properties, whereas oxylipins with inflammation-resolving properties were reduced. $\mathrm{KrO}$ treatment appeared to counteract these HFD-evoked changes. These KrOdependent changes of the inflammatory tone within eWAT and the liver can, at least partly, 
be explained by the ingested PUFAs, and similar effects may occur in other species. In a human study, it has been shown that a linear dose-response relationship exists between the intake of EPA and DHA and the levels of anti-inflammatory oxylipins measured in plasma [72]. This suggests that the direct effects of $\mathrm{KrO}$ on oxylipin tissue concentrations observed herein may also be achievable with dietary regimens in humans.

\section{Conclusions}

We have demonstrated that long-term $\mathrm{KrO}$ treatment $(28 \mathrm{w})$ improves the fatty acid composition in the circulation, WAT and the liver. This improvement is characterized by marked elevations in omega-3 FAs and associated oxylipins, which can exert beneficial effects on metabolism (e.g., fasting insulin, adipokines) and tissue inflammation. Functional gene expression and pathway analyses, combined with lipidomic analyses, provide rationales for direct and indirect effects of KrO-derived PUFAs and oxylipins on metabolic and inflammatory pathways controlled by PPAR $\alpha / \operatorname{PPAR} \gamma$. The stimulatory effect of $\mathrm{KrO}$ on adipogenesis and hyperplasia allows for the safe storage of excess fat in adipose tissue and contributes indirectly to the suppression of inflammation. This indirect effect complements the more direct mechanisms that intercept inflammatory pathways on the molecular level.

Supplementary Materials: The following are available online at https:/ /www.mdpi.com/article/10 .3390/nu13082836/s1, Figure S1: PDX identification based on comparisons with a standard for PDX, Figure S2: $\mathrm{RvE}_{2}$ identification based on comparisons with a $\mathrm{RvE}_{2}$ standard, Table $\mathrm{S} 1$. Individually optimized LC-MS/MS parameters for each compound, Table S2. Fatty acid composition of dried blood spots and eWAT and liver tissue.

Author Contributions: Conceptualization, E.G., K.S., M.C.M., I.B.-P., J.K., A.B.S., P.-A.H. and R.K.; data curation, E.G., K.S., W.v.D., M.C. and M.H.; formal analysis, E.G., M.C., M.H. and M.G.; funding acquisition, K.S., M.C.M., M.G., I.B.-P., A.B.S., P.-A.H. and R.K.; investigation, E.G., K.S., W.v.D., M.C. and M.H.; methodology, E.G., K.S., M.C.M., M.H., M.G., A.B.S., P.-A.H. and R.K.; project administration, E.G., K.S., M.C.M., M.G., I.B.-P., A.B.S., P.-A.H. and R.K.; resources, E.G.; supervision, K.S., W.v.D., I.B.-P., J.K. and R.K.; visualization, E.G. and R.K.; writing-original draft, E.G. and R.K.; writing-review and editing, E.G., K.S., M.C.M., M.C., M.H., M.G., I.B.-P., J.K. and R.K. All authors have read and agreed to the published version of the manuscript.

Funding: This study was performed within the public-private partnership (PPP) ProLiver, a collaboration project that is co-funded by a PPP Allowance made available by Health $\sim$ Holland, Top Sector Life Sciences and Health, to stimulate public-private partnerships. Aker Biomarine was one of the private partners that contributed funding to the PPP ProLiver. The work was also supported by the TNO program Biomedical Health and the oxylipin measurement was funded by ZonMW (The Enabling Technologies Hotels program, grant: 435005007, 2020).

Institutional Review Board Statement: All animal experiments were performed in accordance with the Animal Care and Use Committee and ethical approval by an independent Animal Welfare Body (IVD TNO; approval number 3682/TNO-274).

Informed Consent Statement: Not applicable.

Data Availability Statement: The gene expression data is publicly available on gene expression omnibus, data set GSE179396.

Acknowledgments: We would like to thank Christa de Ruiter and Joline Attema for their technical assistance with the in-life experiment.

Conflicts of Interest: E.G., K.S., M.C.M., M.C., W.v.D., I.B.-P. and R.K. (all TNO): none. M.H. and M.G. (LUMC): none. J.K. (WU): none. A.B.S. and P.-A.H. (Aker Biomarine): Aker Biomarine provided a part of the funding for this study. The funders had no role in data collection and raw data analysis, decision to publish, or preparation of the manuscript.

\section{References}

1. Hotamisligil, G.S. Inflammation, metaflammation and immunometabolic disorders. Nature 2017, 542, 177-185. [CrossRef] 
2. Longo, M.; Zatterale, F.; Naderi, J.; Parrillo, L.; Formisano, P.; Raciti, G.A.; Beguinot, F.; Miele, C. Adipose tissue dysfunction as determinant of obesity-associated metabolic complications. Int. J. Mol. Sci. 2019, 20, 2358. [CrossRef]

3. Mulder, P.; Morrison, M.C.; Wielinga, P.Y.; Van Duyvenvoorde, W.; Kooistra, T.; Kleemann, R. Surgical removal of inflamed epididymal white adipose tissue attenuates the development of non-alcoholic steatohepatitis in obesity. Int. J. Obes. 2016, 40, 675-684. [CrossRef]

4. Morrison, M.C.; Kleemann, R. Role of macrophage migration inhibitory factor in obesity, insulin resistance, type 2 diabetes, and associated hepatic co-morbidities: A comprehensive review of human and rodent studies. Front. Immunol. 2015, 6, 308. [CrossRef]

5. Ellulu, M.S.; Patimah, I.; Khaza'ai, H.; Rahmat, A.; Abed, Y. Obesity \& inflammation: The linking mechanism \& the complications. Arch. Med. Sci. 2017, 13, 851-863.

6. Shashaj, B.; Bedogni, G.; Graziani, M.P.; Tozzi, A.E.; DiCorpo, M.L.; Morano, D.; Tacconi, L.; Veronelli, P.; Contoli, B.; Manco, M. Origin of cardiovascular risk in overweight preschool children: A cohort study of cardiometabolic risk factors at the onset of obesity. JAMA Pediatr. 2014, 168, 917-924. [CrossRef]

7. Winther, B.; Hoem, N.; Berge, K.; Reubsaet, L. Elucidation of phosphatidylcholine composition in krill oil extracted from Euphausia superba. Lipids 2011, 46, 25-36. [CrossRef]

8. Bannenberg, G.L.; Chiang, N.; Ariel, A.; Arita, M.; Tjonahen, E.; Gotlinger, K.H.; Hong, S.; Serhan, C.N. Molecular Circuits of Resolution: Formation and Actions of Resolvins and Protectins. J. Immunol. 2005, 174, 4345-4355. [CrossRef] [PubMed]

9. Krey, G.; Braissant, O.; L'Horset, F.; Kalkhoven, E.; Perroud, M.; Parker, M.G.; Wahli, W. Fatty acids, eicosanoids, and hypolipidemic agents identified as ligands of peroxisome proliferator-activated receptors by coactivator-dependent receptor ligand assay. Mol. Endocrinol. 1997, 11, 779-791. [CrossRef] [PubMed]

10. Korbecki, J.; Bobiński, R.; Dutka, M. Self-regulation of the inflammatory response by peroxisome proliferator-activated receptors. Inflamm. Res. 2019, 68, 443-458. [CrossRef] [PubMed]

11. Ricote, M.; Glass, C.K. PPARs and molecular mechanisms of transrepression. Biochim. Biophys. Acta-Mol. Cell Biol. Lipids 2007, 1771, 926-935. [CrossRef]

12. Gervois, P.; Fruchart, J.C.; Staels, B. Drug insight: Mechanisms of action and therapeutic applications for agonists of peroxisome proliferator-activated receptors. Nat. Clin. Pract. Endocrinol. Metab. 2007, 3, 145-156. [CrossRef] [PubMed]

13. Surette, M.E. The science behind dietary omega-3 fatty acids. CMAJ 2008, 178, 177-180. [CrossRef] [PubMed]

14. Calder, P.C. Omega-3 polyunsaturated fatty acids and inflammatory processes: Nutrition or pharmacology? Br. J. Clin. Pharmacol. 2013, 75, 645-662. [CrossRef] [PubMed]

15. Tillander, V.; Bjørndal, B.; Burri, L.; Bohov, P.; Skorve, J.; Berge, R.K.; Alexson, S.E. Fish oil and krill oil supplementations differentially regulate lipid catabolic and synthetic pathways in mice. Nutr. Metab. 2014, 11, 20. [CrossRef] [PubMed]

16. Tou, J.C.; Altman, S.N.; Gigliotti, J.C.; Benedito, V.A.; Cordonier, E.L. Different sources of omega-3 polyunsaturated fatty acids affects apparent digestibility, tissue deposition, and tissue oxidative stability in growing female rats. Lipids Health Dis. 2011, 10, 179. [CrossRef] [PubMed]

17. Fenton, J.I.; Gurzell, E.A.; Davidson, E.A.; Harris, W.S. Red blood cell PUFAs reflect the phospholipid PUFA composition of major organs. Prostaglandins Leukot. Essent. Fat. Acids 2016, 10, 179. [CrossRef]

18. Burri, L.; Johnsen, L. Krill Products: An Overview of Animal Studies. Nutrients 2015, 7, 3300-3321. [CrossRef]

19. Sun, D.; Zhang, L.; Chen, H.; Feng, R.; Cao, P.; Liu, Y. Effects of Antarctic krill oil on lipid and glucose metabolism in C57BL/6J mice fed with high fat diet. Lipids Health Dis. 2017, 16, 218. [CrossRef]

20. Van den Hoek, A.M.; Verschuren, L.; Worms, N.; van Nieuwkoop, A.; de Ruiter, C.; Attema, J.; Menke, A.L.; Caspers, M.P.M.; Radhakrishnan, S.; Salic, K.; et al. A Translational Mouse Model for NASH with Advanced Fibrosis and Atherosclerosis Expressing Key Pathways of Human Pathology. Cells 2020, 9, 2014. [CrossRef]

21. Morrison, M.C.; Verschuren, L.; Salic, K.; Verheij, J.; Menke, A.; Wielinga, P.Y.; Iruarrizaga-Lejarreta, M.; Gole, L.; Yu, W.-M.; Turner, S.; et al. Obeticholic Acid Modulates Serum Metabolites and Gene Signatures Characteristic of Human NASH and Attenuates Inflammation and Fibrosis Progression in Ldlr-/-.Leiden Mice. Hepatol. Commun. 2018, 2, 1513-1532. [CrossRef]

22. Gart, E.; Lima, E.S.; Schuren, F.; De Ruiter, C.G.F.; Attema, J.; Verschuren, L.; Keijer, J.; Salic, K.; Morrison, M.C. Diet-Independent Correlations between Bacteria and Dysfunction of Gut, Adipose Tissue, and Liver: A Comprehensive Microbiota Analysis in Feces and Mucosa of the Ileum and Colon in Obese Mice with NAFLD. Int. J. Mol. Sci. 2019, 20, 1. [CrossRef]

23. Mueller, A.M.; Kleemann, R.; Gart, E.; Van Duyvenvoorde, W.; Verschuren, L.; Caspers, M.; Menke, A.; Krömmelbein, N.; Salic, K.; Burmeister, Y.; et al. Cholesterol Accumulation as a Driver of Hepatic Inflammation Under Translational Dietary Conditions Can Be Attenuated by a Multicomponent Medicine. Front. Endocrinol. 2021, 12, 156. [CrossRef] [PubMed]

24. Van Koppen, A.; Verschuren, L.; van den Hoek, A.M.; Verheij, J.; Morrison, M.C.; Li, K.; Nagabukuro, H.; Costessi, A.; Caspers, M.P.M.; van den Broek, T.J.; et al. Uncovering a Predictive Molecular Signature for the Onset of NASH-Related Fibrosis in a Translational NASH Mouse Model. Cell. Mol. Gastroenterol. Hepatol. 2018, 5, 83-98.e10. [CrossRef] [PubMed]

25. Krebs, M.; Stingl, H.; Nowotny, P.; Weghuber, D.; Bischof, M.; Waldhäusl, W.; Roden, M. Prevention of in vitro lipolysis by tetrahydrolipstatin. Clin. Chem. 2000, 46, 950-954. [CrossRef]

26. Galarraga, M.; Campión, J.; Munõz-Barrutia, A.; Boqué, N.; Moreno, H.; Martínez, J.A.; Milagro, F.; Ortiz-de-Solórzano, C. Adiposoft: Automated software for the analysis of white adipose tissue cellularity in histological sections. J. Lipid Res. 2012, 53, 2791-2796. [CrossRef] [PubMed] 
27. Tengeler, A.C.; Gart, E.; Wiesmann, M.; Arnoldussen, I.A.C.; van Duyvenvoorde, W.; Hoogstad, M.; Dederen, P.J.; Verweij, V.; Geenen, B.; Kozicz, T.; et al. Propionic acid and not caproic acid, attenuates nonalcoholic steatohepatitis and improves (cerebro) vascular functions in obese Ldlr-/-.Leiden mice. FASEB J. 2020, 34, 9575-9593. [CrossRef]

28. Jo, J.; Gavrilova, O.; Pack, S.; Jou, W.; Mullen, S.; Sumner, A.E.; Cushman, S.W.; Periwal, V. Hypertrophy and/or hyperplasia: Dynamics of adipose tissue growth. PLoS Comput. Biol. 2009, 5, e1000324. [CrossRef]

29. Liang, W.; Menke, A.L.; Driessen, A.; Koek, G.H.; Lindeman, J.H.; Stoop, R.; Havekes, L.M.; Kleemann, R.; Van Den Hoek, A.M. Establishment of a general NAFLD scoring system for rodent models and comparison to human liver pathology. PLoS ONE 2014, 9, e115922. [CrossRef]

30. Kleiner, D.E.; Brunt, E.M. Nonalcoholic fatty liver disease: Pathologic patterns and biopsy evaluation in clinical research. Semin. Liver Dis. 2012, 32, 3-13. [CrossRef]

31. Bligh, E.G.; Dyer, W.J. A Rapid Method of Total Lipid Extraction and Purification. Can. J. Biochem. Physiol. 1959, 37, 911-917. [CrossRef] [PubMed]

32. Love, M.I.; Huber, W.; Anders, S. Moderated estimation of fold change and dispersion for RNA-seq data with DESeq2. Genome Biol. 2014, 15, 550. [CrossRef]

33. Skurk, T.; Alberti-Huber, C.; Herder, C.; Hauner, H. Relationship between adipocyte size and adipokine expression and secretion. J. Clin. Endocrinol. Metab. 2007, 92, 1023-1033. [CrossRef]

34. Boucher, J.; Masri, B.; Daviaud, D.; Gesta, S.; Guigné, C.; Mazzucotelli, A.; Castan-Laurell, I.; Tack, I.; Knibiehler, B.; Carpéné, C.; et al. Apelin, a newly identified adipokine up-regulated by insulin and obesity. Endocrinology 2005, 146, 764-1771. [CrossRef]

35. White, P.J.; Arita, M.; Taguchi, R.; Kang, J.X.; Marette, A. Transgenic restoration of long-chain n-3 fatty acids in insulin target tissues improves resolution capacity and alleviates obesity-linked inflammation and insulin resistance in high-fat-fed mice. Diabetes 2010, 59, 3066-3073. [CrossRef] [PubMed]

36. Neuhofer, A.; Zeyda, M.; Mascher, D.; Itariu, B.K.; Murano, I.; Leitner, L.; Hochbrugger, E.E.; Fraisl, P.; Cinti, S.; Serhan, C.N.; et al Impaired local production of proresolving lipid mediators in obesity and 17-HDHA as a potential treatment for obesity-associated inflammation. Diabetes 2013, 62, 1945-1956. [CrossRef]

37. Serhan, C.N. Pro-resolving lipid mediators are leads for resolution physiology. Nature 2014, 510, 92-101. [CrossRef] [PubMed]

38. Morimoto, K.; Shirata, N.; Taketomi, Y.; Tsuchiya, S.; Segi-Nishida, E.; Inazumi, T.; Kabashima, K.; Tanaka, S.; Murakami, M.; Narumiya, S.; et al. Prostaglandin E 2 -EP3 Signaling Induces Inflammatory Swelling by Mast Cell Activation. J. Immunol. 2014, 192, 1130-1137. [CrossRef]

39. Caussy, C.; Chuang, J.-C.; Billin, A.; Hu, T.; Wang, Y.; Subramanian, G.M.; Djedjos, C.S.; Myers, R.P.; Dennis, E.A.; Loomba, R. Plasma eicosanoids as noninvasive biomarkers of liver fibrosis in patients with nonalcoholic steatohepatitis. Therap. Adv. Gastroenterol. 2020, 13, 13. [CrossRef]

40. Maciejewska, D.; Drozd, A.; Skonieczna-Zydecka, K.; Skórka-Majewicz, M.; Dec, K.; Jakubczyk, K.; Pilutin, A.; Stachowska, E. Eicosanoids in nonalcoholic fatty liver disease (NAFLD) progression. Do serum eicosanoids profile correspond with liver eicosanoids content during NAFLD development and progression? Molecules 2020, 25, 2026. [CrossRef]

41. Musso, G.; Gambino, R.; Cassader, M.; Paschetta, E.; Sircana, A. Specialized Proresolving Mediators: Enhancing Nonalcoholic Steatohepatitis and Fibrosis Resolution. Trends Pharmacol. Sci. 2018, 39, 387-401. [CrossRef]

42. Hirai, H.; Tanaka, K.; Yoshie, O.; Ogawa, K.; Kenmotsu, K.; Takamori, Y.; Ichimasa, M.; Sugamura, K.; Nakamura, M.; Takano, S.; et al. Prostaglandin D2 selectively induces chemotaxis in T helper type 2 cells, eosinophils, and basophils via seventransmembrane receptor CRTH2. J. Exp. Med. 2001, 193, 255-262. [CrossRef] [PubMed]

43. Weller, C.L.; Collington, S.J.; Hartnell, A.; Conroy, D.M.; Kaise, T.; Barker, J.E.; Wilson, M.S.; Taylor, G.W.; Jose, P.J.; Williams, T.J. Chemotactic action of prostaglandin E2 on mouse mast cells acting via the PGE2 receptor 3. Proc. Natl. Acad. Sci. USA 2007, 104, 11712-11717. [CrossRef]

44. Tsuge, K.; Inazumi, T.; Shimamoto, A.; Sugimoto, Y. Molecular mechanisms underlying prostaglandin E2-exacerbated inflammation and immune diseases. Int. Immunol. 2019, 31, 597-606. [CrossRef]

45. Titos, E.; Rius, B.; González-Périz, A.; López-Vicario, C.; Morán-Salvador, E.; Martínez-Clemente, M.; Arroyo, V.; Clària, J. Resolvin D1 and Its Precursor Docosahexaenoic Acid Promote Resolution of Adipose Tissue Inflammation by Eliciting Macrophage Polarization toward an M2-Like Phenotype. J. Immunol. 2011, 187, 5408-5418. [CrossRef]

46. González-Périz, A.; Planagumà, A.; Gronert, K.; Miquel, R.; López-Parra, M.; Titos, E.; Horrillo, R.; Ferré, N.; Deulofeu, R.; Arroyo, V.; et al. Docosahexaenoic acid (DHA) blunts liver injury by conversion to protective lipid mediators: Protectin D1 and 17S-hydroxy-DHA. FASEB J. 2006, 20, 2537-2539. [CrossRef]

47. González-Périz, A.; Horrillo, R.; Ferré, N.; Gronert, K.; Dong, B.; Morán-Salvador, E.; Titos, E.; Martínez-Clemente, M.; LópezParra, M.; Arroyo, V.; et al. Obesity-induced insulin resistance and hepatic steatosis are alleviated by $\omega-3$ fatty acids: A role for resolvins and protectins. FASEB J. 2009, 23, 1946-1957. [CrossRef]

48. Meijerink, J.; Poland, M.; Balvers, M.G.J.; Plastina, P.; Lute, C.; Dwarkasing, J.; Van Norren, K.; Witkamp, R.F. Inhibition of COX-2-mediated eicosanoid production plays a major role in the anti-inflammatory effects of the endocannabinoid $\mathrm{N}$ docosahexaenoylethanolamine (DHEA) in macrophages. Br. J. Pharmacol. 2015, 172, 24-37. [CrossRef]

49. Shi, H.; Chen, H.; Gu, Z.; Zhang, H.; Chen, W.; Chen, Y.Q. Application of a delta-6 desaturase with $\alpha$-linolenic acid preference on eicosapentaenoic acid production in Mortierella alpina. Microb. Cell Factories 2016, 15, 117. [CrossRef] 
50. Olga, L.; van Diepen, J.A.; Bobeldijk-Pastorova, I.; Gross, G.; Prentice, P.M.; Snowden, S.G.; Furse, S.; Kooistra, T.; Hughes, I.A.; Schoemaker, M.H.; et al. Lipid ratios representing SCD1, FADS1, and FADS2 activities as candidate biomarkers of early growth and adiposity. EBioMedicine 2021, 63, 103198. [CrossRef]

51. Picklo, M.J.; Idso, J.; Seeger, D.R.; Aukema, H.M.; Murphy, E.J. Comparative effects of high oleic acid vs high mixed saturated fatty acid obesogenic diets upon PUFA metabolism in mice. Prostaglandins Leukot. Essent. Fat. Acids 2017, 119, 25-37. [CrossRef]

52. Strassburg, K.; Huijbrechts, A.M.L.; Kortekaas, K.A.; Lindeman, J.H.; Pedersen, T.L.; Dane, A.; Berger, R.; Brenkman, A.; Hankemeier, T.; Van Duynhoven, J.; et al. Quantitative profiling of oxylipins through comprehensive LC-MS/MS analysis: Application in cardiac surgery. Anal. Bioanal. Chem. 2012, 404, 1413-1426. [CrossRef]

53. Morrison, M.C.; Mulder, P.; Salic, K.; Verheij, J.; Liang, W.; Van Duyvenvoorde, W.; Menke, A.; Kooistra, T.; Kleemann, R.; Wielinga, P.Y. Intervention with a caspase-1 inhibitor reduces obesity-associated hyperinsulinemia, non-alcoholic steatohepatitis and hepatic fibrosis in LDLR-/-.Leiden mice. Int. J. Obes. 2016, 40, 1416-1423. [CrossRef]

54. Hotamisligil, G.S.; Shargill, N.S.; Spiegelman, B.M. Adipose expression of tumor necrosis factor- $\alpha$ : Direct role in obesity-linked insulin resistance. Science 1993, 259, 87-91. [CrossRef]

55. Duffaut, C.; Zakaroff-Girard, A.; Bourlier, V.; Decaunes, P.; Maumus, M.; Chiotasso, P.; Sengenès, C.; Lafontan, M.; Galitzky, J.; Bouloumié, A. Interplay between human adipocytes and T lymphocytes in obesity: CCL20 as an adipochemokine and T lymphocytes as lipogenic modulators. Arterioscler. Thromb. Vasc. Biol. 2009, 29, 1608-1614. [CrossRef]

56. Ruan, H.; Lodish, H.F. Insulin resistance in adipose tissue: Direct and indirect effects of tumor necrosis factor- $\alpha$. Cytokine Growth Factor Rev. 2003, 14, 447-455. [CrossRef]

57. Hers, I.; Tavaré, J.M. Mechanism of feedback regulation of insulin receptor substrate-1 phosphorylation in primary adipocytes. Biochem. J. 2005, 388, 713-720. [CrossRef]

58. Larabee, C.M.; Neely, O.C.; Domingos, A.I. Obesity: A neuroimmunometabolic perspective. Nat. Rev. Endocrinol. 2020, 16, 30-43. [CrossRef]

59. Fang, H.; Judd, R.L. Adiponectin regulation and function. Compr. Physiol. 2018, 8, 1031-1063.

60. Liu, Y.; Turdi, S.; Park, T.; Morris, N.J.; Deshaies, Y.; Xu, A.; Sweeney, G. Adiponectin corrects high-fat diet-induced disturbances in muscle metabolomic profile and whole-body glucose homeostasis. Diabetes 2012, 62, 743-752. [CrossRef]

61. Park, S.K.; Oh, S.Y.; Lee, M.Y.; Yoon, S.; Kim, K.S.; Kim, J.W. CCAAT/enhancer binding protein and nuclear factor-Y regulate adiponectin gene expression in adipose tissue. Diabetes 2004, 53, 2757-2766. [CrossRef]

62. Matassa, D.S.; Amoroso, M.R.; Maddalena, F.; Landriscina, M.; Esposito, F. New insights into TRAP1 pathway. Am. J. Cancer Res. 2012, 2, 235-248.

63. Rosen, E.D.; MacDougald, O.A. Adipocyte differentiation from the inside out. Nat. Rev. Mol. Cell Biol. 2006, 7, 885-896. [CrossRef] [PubMed]

64. Moseti, D.; Regassa, A.; Kim, W.K. Molecular regulation of adipogenesis and potential anti-adipogenic bioactive molecules. Int. J. Mol. Sci. 2016, 17, 124. [CrossRef] [PubMed]

65. Flachs, P.; Horakova, O.; Brauner, P.; Rossmeisl, M.; Pecina, P.; Franssen-Van Hal, N.; Ruzickova, J.; Sponarova, J.; Drahota, Z.; Vlcek, C.; et al. Polyunsaturated fatty acids of marine origin upregulate mitochondrial biogenesis and induce $\beta$-oxidation in white fat. Diabetologia 2005, 48, 2365-2375. [CrossRef]

66. Cho, E.; Jung, W.; Joo, H.-Y.; Park, E.-R.; Kim, M.-Y.; Kim, S.-B.; Kim, K.S.; Bin Lim, Y.; Lee, K.H.; Shin, H.J. Cluh plays a pivotal role during adipogenesis by regulating the activity of mitochondria. Sci. Rep. 2019, 9, 6820. [CrossRef]

67. Mulder, P.; Morrison, M.C.; Verschuren, L.; Liang, W.; Van Bockel, J.H.; Kooistra, T.; Wielinga, P.Y.; Kleemann, R. Reduction of obesity-associated white adipose tissue inflammation by rosiglitazone is associated with reduced non-alcoholic fatty liver disease in LDLr-deficient mice. Sci. Rep. 2016, 6, 31542. [CrossRef]

68. Zhang, Y.; Chua, S. Leptin function and regulation. Compr. Physiol. 2018, 8, 351-369.

69. Delerive, P.; De Bosscher, K.; Besnard, S.; Berghe, W.V.; Peters, J.M.; Gonzalez, F.J.; Fruchart, J.C.; Tedgui, A.; Haegeman, G.; Staels, B. Peroxisome proliferator-activated receptor $\alpha$ negatively regulates the vascular inflammatory gene response by negative cross-talk with transcription factors NF- $\mathrm{kB}$ and AP-1. J. Biol. Chem. 1999, 274, 32048-32054. [CrossRef]

70. Cinti, S. Adipose Organ Development and Remodeling. Compr. Physiol. 2018, 8, 1357-1431. [PubMed]

71. Rossmeisl, M.; Macek Jilkova, Z.; Kuda, O.; Jelenik, T.; Medrikova, D.; Stankova, B.; Kristinsson, B.; Haraldsson, G.G.; Svensen, H.; Stoknes, I.; et al. Metabolic effects of n-3 PUFA as phospholipids are superior to triglycerides in mice fed a high-fat diet: Possible role of endocannabinoids. PLoS ONE 2012, 7, e38834. [CrossRef] [PubMed]

72. Ostermann, A.I.; West, A.L.; Schoenfeld, K.; Browning, L.M.; Walker, C.G.; Jebb, S.A.; Calder, P.C.; Schebb, N.H. Plasma oxylipins respond in a linear dose-response manner with increased intake of EPA and DHA: Results from a randomized controlled trial in healthy humans. Am. J. Clin. Nutr. 2019, 109, 1251-1263. [CrossRef] [PubMed] 